\title{
Explicit modelling of SOA formation from $\alpha$-pinene photooxidation: sensitivity to vapour pressure estimation
}

\author{
R. Valorso ${ }^{1}$, B. Aumont ${ }^{1}$, M. Camredon ${ }^{1}$, T. Raventos-Duran ${ }^{1}$, C. Mouchel-Vallon ${ }^{1}$, N. L. Ng$^{2}$, J. H. Seinfeld ${ }^{3}$, \\ J. Lee-Taylor ${ }^{4}$, and S. Madronich ${ }^{4}$ \\ ${ }^{1}$ LISA, UMR CNRS/INSU 7583, Université Paris Est Créteil et Université Paris Diderot, Institut Pierre Simon Laplace, \\ 94010 Créteil Cedex, France \\ ${ }^{2}$ Aerodyne Research, Inc. Billerica, MA 01821, USA \\ ${ }^{3}$ California Institute of Technology, Pasadena, CA 91125, USA \\ ${ }^{4}$ Atmospheric Chemistry Division, NCAR, Boulder, CO, USA
}

Received: 24 March 2011 - Published in Atmos. Chem. Phys. Discuss.: 29 March 2011

Revised: 28 June 2011 - Accepted: 8 July 2011 - Published: 18 July 2011

\begin{abstract}
The sensitivity of the formation of secondary organic aerosol (SOA) to the estimated vapour pressures of the condensable oxidation products is explored. A highly detailed reaction scheme was generated for $\alpha$-pinene photooxidation using the Generator for Explicit Chemistry and Kinetics of Organics in the Atmosphere (GECKO-A). Vapour pressures $\left(P^{\text {vap }}\right)$ were estimated with three commonly used structure activity relationships. The values of $P^{\text {vap }}$ were compared for the set of secondary species generated by GECKO-A to describe $\alpha$-pinene oxidation. Discrepancies in the predicted vapour pressures were found to increase with the number of functional groups borne by the species. For semi-volatile organic compounds (i.e. organic species of interest for SOA formation), differences in the predicted $P^{\mathrm{vap}}$ range between a factor of 5 to 200 on average. The simulated SOA concentrations were compared to SOA observations in the Caltech chamber during three experiments performed under a range of $\mathrm{NO}_{\mathrm{x}}$ conditions. While the model captures the qualitative features of SOA formation for the chamber experiments, SOA concentrations are systematically overestimated. For the conditions simulated, the modelled SOA speciation appears to be rather insensitive to the $P^{\text {vap }}$ estimation method.
\end{abstract}

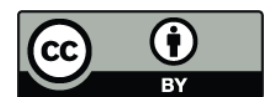

Correspondence to: B. Aumont (bernard.aumont@lisa.u-pec.fr)

\section{Introduction}

Secondary organic aerosols have a substantial impact on human health, visibility and climate (e.g. Hallquist et al., 2009). The environmental impacts of SOA depend on their physico-chemical properties and therefore their composition (e.g. Fuzzi et al., 2006). SOA are formed by condensation of gaseous secondary organics produced during Volatile Organic Compound (VOC) oxidation. The gas/particle partitioning of each organic follows an absorption process (e.g. Pankow, 1994) that can be described by:

$P_{i}=x_{i} \gamma_{i} P_{i}^{\text {vap }}$

where $P_{i}$ is the partial pressure of the species $i, x_{i}$ its mole fraction in the condensed phase, $\gamma_{i}$ its activity coefficient and $P_{i}^{\text {vap }}$ its saturation vapour pressure (atm). At thermodynamic equilibrium, the condensed fraction of the total amount of compound $i$ in the air, $\xi_{i}^{\text {aer }}$, can be expressed as (e.g. Donahue et al., 2009):

$\xi_{i}^{\mathrm{aer}}=\frac{N_{i, \text { aer }}}{N_{i, \text { aer }}+N_{i, \text { gas }}}=\frac{1}{1+\frac{\overline{M_{\text {aer }} \gamma_{i}} P_{i}^{\text {vap }}}{C_{\text {aer }} R T} \times 10^{6}}$

where $N_{i, \text { gas }}$ and $N_{i, \text { aer }}$ are the number concentration (molecule $\mathrm{cm}^{-3}$ of air) of species $i$ in the gas and aerosol phase, respectively, $\overline{M_{\text {aer }}}$ is the mean organic molar mass in the aerosol $\left(\mathrm{g} \mathrm{mol}^{-1}\right), C_{\text {aer }}$ the total organic aerosol mass concentration $\left(\mu \mathrm{g} \mathrm{m}^{-3}\right.$ of air), $R$ the ideal gas constant (atm m $\mathrm{K}^{3} \mathrm{~K}^{-1} \mathrm{~mol}^{-1}$ ) and $T$ the temperature (K). Figure 1 shows the variation of $\xi_{i}^{\text {aer }}$ as a function of the saturation vapour pressure of a given species under typical atmospheric

Published by Copernicus Publications on behalf of the European Geosciences Union. 


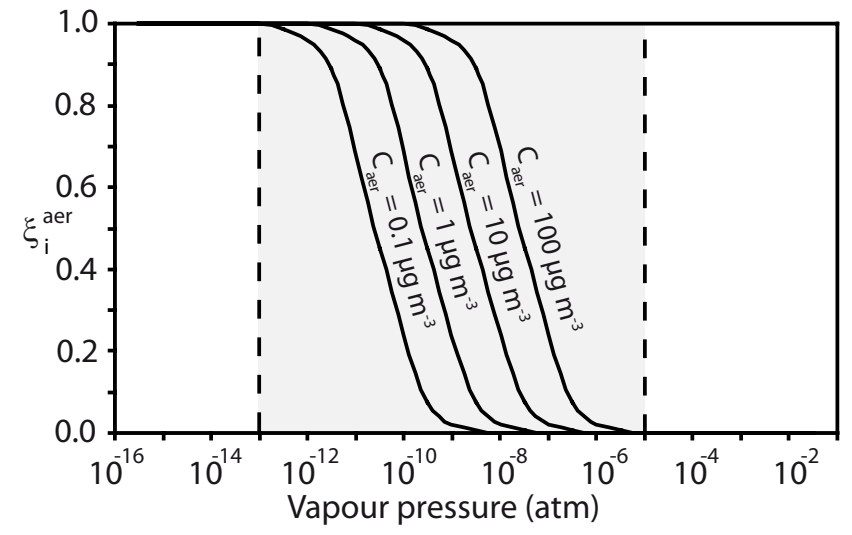

Fig. 1. Fraction $\xi_{i}^{\mathrm{aer}}$ in the aerosol phase at thermodynamic equilibrium as a function of the saturation vapour pressure of the species considered and for typical atmospheric aerosol concentrations. The calculation is performed assuming an ideal mixture in the condensed phase and mean molar mass of $200 \mathrm{~g} \mathrm{~mol}^{-1}$. Shaded area represents the vapour pressure range where significant partitioning of the species may occur under atmospheric conditions at equilibrium.

aerosol concentrations. The volatility of organic compounds can be divided into 3 categories (see Fig. 1):

- species having a vapour pressure below $10^{-13} \mathrm{~atm}$. These species will be mostly in the aerosol phase $\left(\xi_{i}^{\text {aer }}>\right.$ $0.99)$ even for a low aerosol concentration $\left(0.1 \mu \mathrm{g} \mathrm{m}^{-3}\right)$. This category can therefore be qualified as non-volatile under atmospheric conditions.

- species having a vapour pressure above $10^{-5} \mathrm{~atm}$. These species will be mostly in the gas phase $\left(\xi_{i}^{\text {aer }}<0.01\right)$ even for a high aerosol concentration $\left(100 \mu \mathrm{g} \mathrm{m}^{-3}\right)$. This category can therefore be considered as volatile under atmospheric conditions.

- species having a vapour pressure ranging between $10^{-13}$ and $10^{-5} \mathrm{~atm}$. These species are expected to be present in both phases depending on the aerosol load. This category can be qualified as semi-volatile under atmospheric conditions.

A large number of secondary species are formed during VOC oxidation (e.g. Aumont et al., 2005; Goldstein and Galbally, 2007; Kroll et al., 2011). A detailed model describing SOA formation needs vapour pressure data for each secondary organic species produced during gas-phase oxidation. Explicit $P^{\text {vap }}$ data needed to represent the gas/particle partitioning for the myriad of secondary species are generally not available. Structure Activity Relationships (SAR) are therefore used to estimate $P^{\text {vap }}$ in SOA formation models (e.g. Camredon et al., 2007, 2010; Capouet et al., 2008; Xia et al., 2008). Several SAR devoted to the estimation of $P^{\text {vap }}$ are available in the literature (Capouet and Müller, 2006; Myrdal and Yalkowsky, 1997; Moller et al., 2008; Nannoolal et al., 2008; Pankow and Asher, 2008). The differences in the $P^{\text {vap }}$ estimated by available SAR can reach orders of magnitudes for species in the $P^{\text {vap }}$ range of $10^{-13}$ and $10^{-5}$ atm (e.g. Camredon and Aumont, 2006; Clegg et al., 2008; Compernolle et al., 2010; Booth et al., 2011). The objective of this study is to evaluate the sensitivity of predicted SOA formation to $P^{\text {vap }}$ estimates.

Three vapour pressure estimation methods were tested in this study: the Myrdal and Yalkowsky (1997) method (referred hereafter as JR/MY), the Nannoolal et al. (2008) method (hereafter NAN/NAN) and the SIMPOL-1 method from Pankow and Asher (2008) (hereafter SIM). The JR/MY method is developed on the basis of the Clausius-Clapeyron equation. Vapour pressure is estimated as a function of the temperature through a relatively simple formula, involving the boiling point $\left(T_{\mathrm{b}}\right)$ and structural properties (the effective torsional bond number and the hydrogen bond number). The Joback group contribution method (Joback and Reid, 1987) was used to estimate $T_{\mathrm{b}}$. This method involves 29 group contributions. The JR/MY method was implemented as described by Myrdal and Yalkowsky (1997) for $P^{\text {vap }}$ and Joback and Reid (1987) for $T_{\mathrm{b}}$ with the group contributions for $-\mathrm{OOH}, \mathrm{C}(=\mathrm{O}) \mathrm{OONO}_{2}$ and $-\mathrm{ONO}_{2}$ specified in Camredon and Aumont (2006). The NAN/NAN method is also based on the Clausius-Clapeyron equation. The method estimates $P^{\text {vap }}$ as a function of $T_{\mathrm{b}}$ and 212 group contributions and interaction corrections. Boiling points were estimated using the Nannoolal method (Nannoolal et al., 2004) which involves the same type of groups. The NAN/NAN method was implemented as described by Nannoolal et al. $(2004,2008)$ with group contribution values for $-\mathrm{OOH}, \mathrm{C}(=\mathrm{O}) \mathrm{OOH}$ and $\mathrm{C}(=\mathrm{O}) \mathrm{OONO}_{2}$ taken from Compernolle et al. (2010). The SIM method is an empirical method specifically developed for the purpose of simulating SOA formation (Pankow and Asher, 2008). It is very simple to use as it provides $P^{\text {vap }}$ directly from 30 group contributions.

Recent studies have assessed SAR reliability against experimental data for species of interest in SOA formation. The JR/MY method was shown to provide good estimates of $P^{\text {vap }}$ for a set of organic species of interest for SOA formation (Camredon and Aumont, 2006). Barley and McFiggans (2010) have compared JR/MY estimates with a different experimental database showing that the JR/MY method underestimates $P^{\text {vap }}$, mainly because of $T_{\mathrm{b}}$ overestimation. Barley and McFiggans (2010) have identified the NAN/NAN method as the more reliable one to estimate $P^{\text {vap }}$ for the purpose of SOA formation. Nevertheless, Booth et al. (2010, 2011) have compared various methods for acids and diacids and showed that NAN/NAN does not always give the best results. However, very few experimental data are available for species having a vapour pressure below $10^{-8} \mathrm{~atm}$. The reliability of the SAR remains thus difficult to assess for the semi-volatile organic compounds of interest in the context of SOA formation. 
The influence of $P^{\text {vap }}$ estimation method on SOA formation was simulated for SOA formed during $\alpha$-pinene photooxidation under various $\mathrm{NO}_{\mathrm{x}}$ levels. The three $P^{\mathrm{vap}} \mathrm{SAR}$ were implemented in a detailed model for SOA formation. The chemical schemes were generated using the Generator for Explicit Chemistry and Kinetics of Organics in the Atmosphere (GECKO-A) (Aumont et al., 2005; Camredon et al., 2007). Observations from the California Institute of Technology (Caltech) laboratory chamber ( $\mathrm{Ng}$ et al., 2007) were selected to test the sensitivity of the simulated SOA mass concentration and speciation to $P^{\text {vap }}$ estimates. Modelling tools are described in Sect. 2. The vapour pressures estimated with the three SAR adopted for this study are presented in Sect. 3 for secondary products generated by GECKO-A during $\alpha$-pinene oxidation. Section 4 is devoted to sensitivity tests of $P^{\text {vap }}$ estimation methods for SOA formation and the comparison of the modelling results with observations in the laboratory chamber. Finally, the simulated results are used to explore the influence of $\mathrm{NO}_{\mathrm{x}}$ on gaseous and condensed organic properties in Sect. 5.

\section{Modelling tools}

\section{$2.1 \alpha$-pinene gaseous oxidation schemes}

Compounds of interest for SOA formation are multifunctional species formed during the progressive gaseous oxidation of organic matter. The description of the formation of semi-volatile compounds and their partitioning between phases requires the use of explicit chemical mechanisms. Fully explicit chemical schemes that involve a large number of secondary species far exceed the size of chemical schemes that can be written manually for long chain alkanes $(C>6)$. The detailed $\alpha$-pinene oxidation scheme was generated using the GECKO-A computer program (Aumont et al., 2005; Camredon et al., 2007). GECKO-A generates chemical schemes according to a prescribed protocol (Aumont et al., 2005), assigning reaction pathways and kinetics data, on the basis of experimental data and structure activity relationships.

The number of species needed to describe explicitly the oxidation of a precursor increases exponentially with the size of its carbon skeleton (Aumont et al., 2005). GECKO-A generates an explicit oxidation chemical scheme of about 1 million species for octene (Camredon et al., 2007), close to current computational limits. Fully explicit chemical schemes generated with GECKO-A are limited to precursors with up to 8 carbon atoms. We therefore implemented a reduction protocol in GECKO-A to allow generation of oxidation schemes for $\mathrm{C}>8$ hydrocarbons. The reduction protocol was designed to keep the oxidation schemes as detailed as possible, without losing the chemical information that determines organic species properties such as the reactivity or the volatility. The reduction protocol includes:
Table 1. Criteria used in the reduction protocol using surrogate species for position isomer (see text).

\begin{tabular}{|c|c|}
\hline & Criteria \\
\hline 1 & \# of $\mathrm{CH}_{3}$ groups \\
\hline 2 & \# of $\mathrm{CH}_{2}$ groups \\
\hline 3 & \# of $\mathrm{CH}$ groups \\
\hline 4 & \# of C groups \\
\hline 5 & \# of primary nodes (ending position) ${ }^{\mathrm{a}}$ \\
\hline 6 & \# of secondary nodes ${ }^{\mathrm{a}}$ \\
\hline 7 & \# of tertiary nodes (branching position) ${ }^{\mathrm{a}}$ \\
\hline 8 & \# of quaternary nodes $(2 \text { branching })^{\mathrm{a}}$ \\
\hline 9 & \# of conjugated carbonyls (-CO-CO- structures) \\
\hline 10 & \# of functional groups in $1-2$ position \\
\hline 11 & \# of functional groups in $1-3$ position \\
\hline 12 & \# of functional groups in $1-4$ position \\
\hline 13 & \# of conjugated carbonyls at a terminal end of the chain \\
\hline 14 & \# of $-\mathrm{CH}_{2} \mathrm{CH}_{3}$ groups \\
\hline 15 & $\#$ of $-\mathrm{CH}_{2} \mathrm{CH}_{2} \mathrm{CH}_{3}$ groups \\
\hline 16 & \# of $-\mathrm{CH}_{2} \mathrm{CH}_{2} \mathrm{CH}_{2} \mathrm{CH}_{3}$ groups \\
\hline 17 & \# of -CO-CHO groups \\
\hline 18 & \# of - $\left.\mathrm{CO}-\mathrm{CO}(\mathrm{OONO})_{2}\right)$ groups \\
\hline 19 & \# of $-\mathrm{CO}-\mathrm{CO}(\mathrm{OH})$ groups \\
\hline 20 & \# of - $\mathrm{CO}-\mathrm{CO}(\mathrm{OOH})$ groups \\
\hline
\end{tabular}

a Primary, secondary, tertiary and quaternary nodes are carbon atoms bound to 1, 2, 3 or 4 other carbon atoms of the skeleton, respectively.

- the elimination of non-volatile species from the gaseous chemical schemes. As discussed previously, a species can be considered as non-volatile under atmospheric conditions if its vapour pressure is below $10^{-13} \mathrm{~atm}$. The species is almost non-existent in the gaseous phase and its gas phase oxidation should not be significant. Gas-phase chemistry was thus not generated for species having a vapour pressure below $10^{-13} \mathrm{~atm}$.

- the substitution of species by isomers. The number of isomers increases exponentially with the size of the molecule (e.g. Goldstein and Galbally, 2007). This method is then expected to be more effective when the carbon chain is long. The reduction protocol was constrained to allow the substitution of one species by another only if the two molecules are position isomers, i.e. the two molecules differ only by the position of functional groups on the carbon skeleton. Substitution is not allowed for species bearing a $\mathrm{C}=\mathrm{C}$ bond. In addition, isomer substitutions were restricted according to the maximum production yields of secondary species. No substitution is allowed if the production yield of a species is greater than $5 \times 10^{-3}$. Species having a production yield ranging from $5 \times 10^{-3}$ to $1 \times 10^{-3}$ are substituted in the scheme if both the species and its surrogate match exactly the 20 criteria listed in Table 1 . For species having a production yield lower than $1 \times 10^{-3}$, 


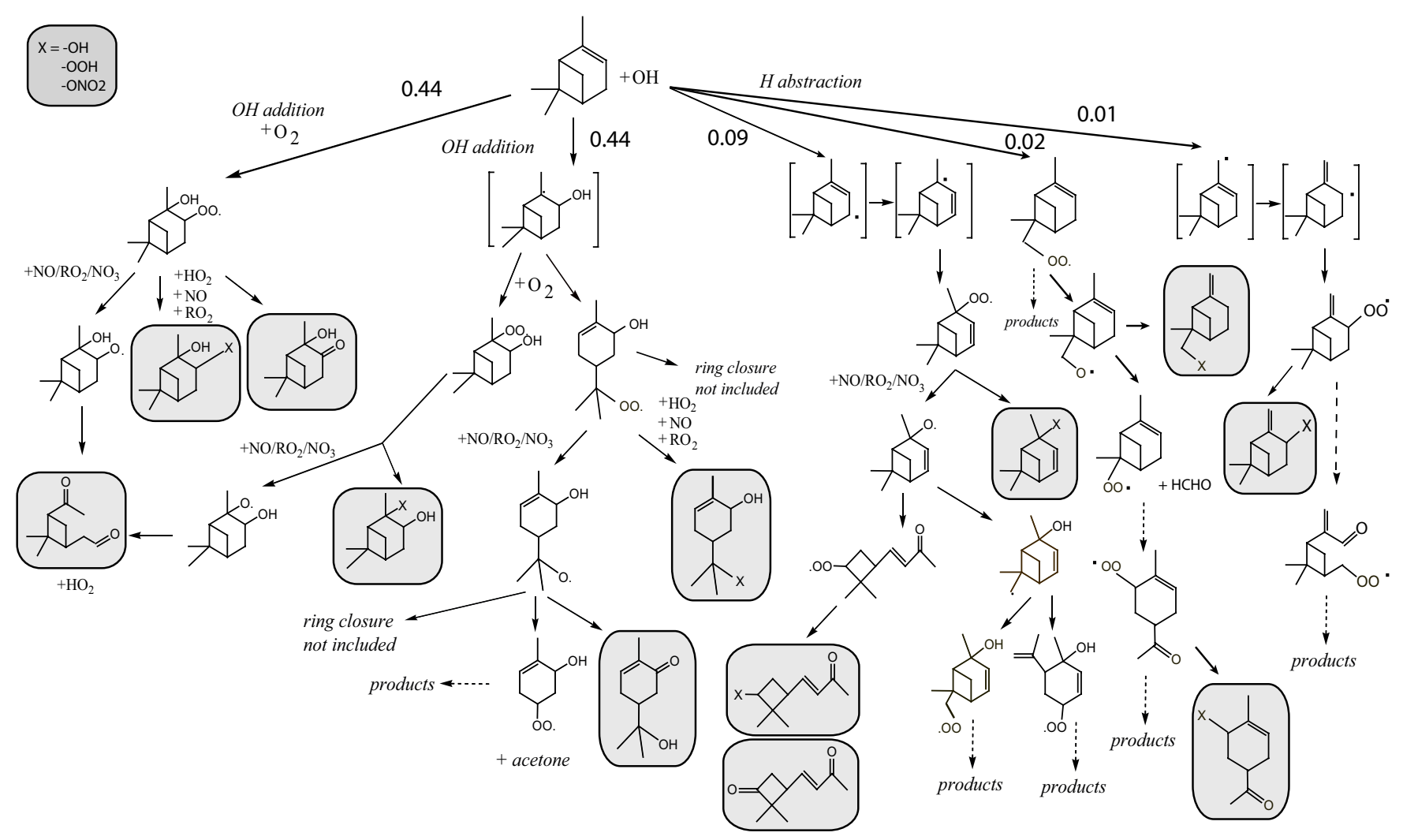

Fig. 2. First oxidation steps of the $\alpha$-pinene oxidation by $\mathrm{OH}$ as represented in GECKO-A. Framed compounds represent stable species.

the criteria listed in Table 1 are used to discriminate among various possible position isomers. The program scrolls down the list of the 20 criteria until one isomer remains. If more than one isomer remains at the end of the process, the one with the highest yield is kept as surrogate. These threshold values for the production yields were optimised to achieve the best compromise between accuracy and size of the chemical scheme. Comparisons performed with the explicit and reduced chemical schemes have shown that these reductions have a negligible influence on simulated ozone, gaseous and condensed secondary compound speciation, and SOA mass.

In this study, specific constraints were placed on the first oxidation pathways for the generated $\alpha$-pinene chemical scheme by using branching ratios of the first $\mathrm{OH}$-initiated chemical pathways of $\alpha$-pinene, as theoretically calculated by Peeters et al. (2001). In addition, reactions specific to $\alpha$-pinene chemistry, such as the breaking of the four-membered ring of the $\alpha$-hydroxy alkyl radical formed after $\mathrm{OH}$ addition, have been identified in the literature. As there is not enough evidence to generalize this pathway to other species, this reaction was not implemented in the GECKO-A protocol but manually added to the mechanism (see Fig. 2). Peeters et al. (2001) proposed from theoretical studies that this reaction competes with the usual peroxy radical pathways. Branch- ing ratios for these reaction pathways were set to 50:50 in GECKO-A based on the recommendation by Peeters et al. (2001).

Figures 2 and 3 show reaction pathways included in GECKO-A for the $\alpha$-pinene $+\mathrm{OH}$ and $\alpha$-pinene $+\mathrm{O}_{3}$ reactions up to the formation of the first-generation stable products. GECKO-A also provides vapour pressures for every species included in the chemical scheme. The $\alpha$-pinene oxidation scheme generated with GECKO-A was then interfaced with the JR/MY, SIM and NAN/NAN vapour pressure estimates. As the reduction protocol depends on vapour pressure, the size of the generated chemical scheme differs according to the SAR used (see Sect. 3). For $\alpha$-pinene oxidation, the generated scheme includes $2.05 \times 10^{5}, 3.98 \times 10^{5}$ and $5.30 \times 10^{5}$ species using JR/MY, NAN/NAN and SIM, respectively.

\subsection{The box-model for SOA formation}

The detailed $\alpha$-pinene chemical scheme was implemented in a box-model. Time integration of chemical schemes is solved using the two-step solver (Verwer et al., 1994, 1996). The gas/particle partitioning of organics was implemented as described by Camredon et al. (2007), solving Eq. (1) with the assumption of ideality $\left(\gamma_{i}=1\right)$. Thermodynamic equilibrium is forced at each time step of $1 \mathrm{~min}$ and solved by the iterative 


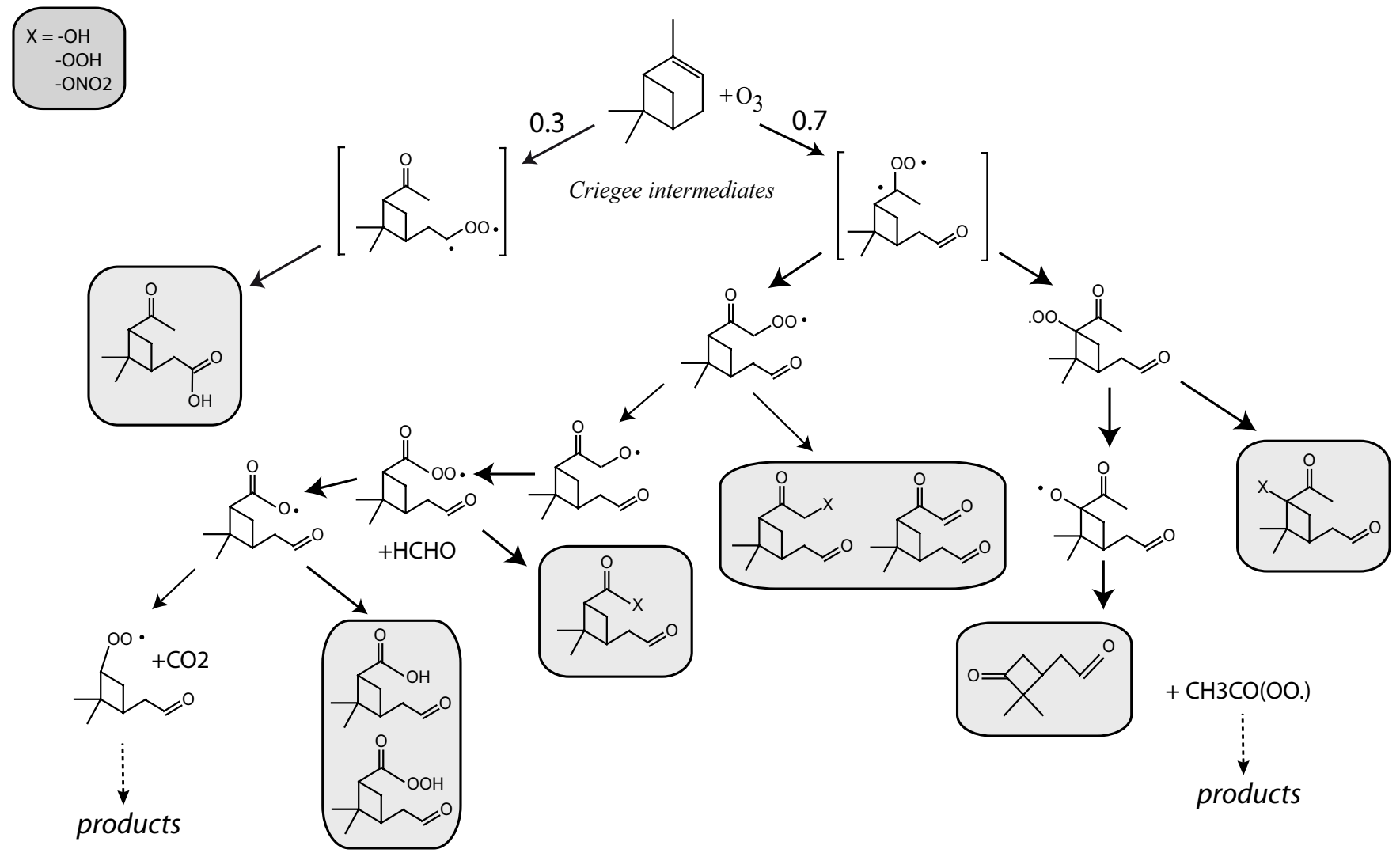

Fig. 3. First oxidation steps of the $\alpha$-pinene oxidation by ozone as represented in GECKO-A. Framed compounds represent stable species.
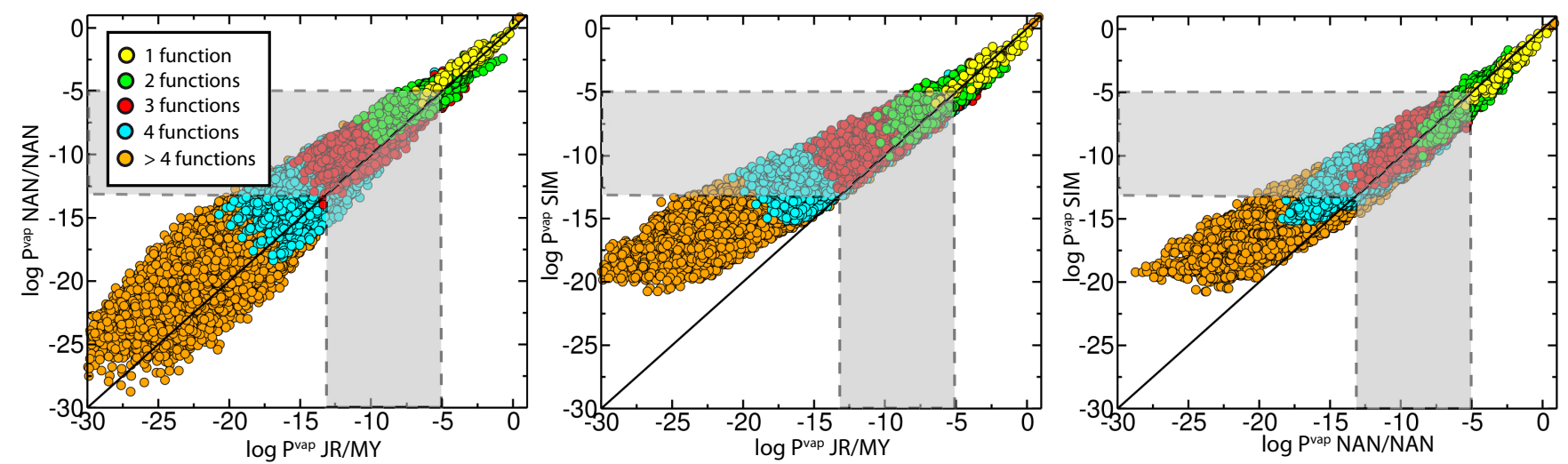

Fig. 4. Scatter plot of $P^{\text {vap }}$ estimated by JR/MY, NAN/NAN and SIM for the secondary species generated during $\alpha$-pinene oxidation. Shaded areas define the semi-volatile domain of particular interest for atmospheric applications $\left(10^{-13}\right.$ and $\left.10^{-5} \mathrm{~atm}\right)$.

method described by Pankow (1994). No reactions are assumed to be occurring in the condensed phase.

\section{Comparison of vapour pressure estimates}

Vapour pressures estimated with JR/MY, NAN/NAN and SIM were compared for the set of secondary species generated by GECKO-A to describe $\alpha$-pinene oxidation, i.e. for about $1.2 \times 10^{5}$ stable species. Figure 4 presents the scatter plots for the $P^{\text {vap }}$ computed at $298 \mathrm{~K}$ with the three estimation methods. Differences in the predicted values were examined for various subsets of species. Two categories of subsets were defined according to: (1) the number of functional groups (i.e. monofunctional, difunctional, trifunctional and multifunctional species) and (2) the volatility (i.e. volatile, semi-volatile and non-volatile species). Table 2 lists the 
Table 2. Mean average differences (MAD) and mean differences (MD) between JR/MY-SIM, JR/MY-NAN/NAN, SIM-NAN/NAN, for (1) mono-functional, di-functional, tri-functional and multifunctional species and (2) for non volatile, semi-volatile and volatile species.

\begin{tabular}{|c|c|c|c|c|c|c|c|}
\hline & $\begin{array}{r}1 \text { functional } \\
\text { group }\end{array}$ & $\begin{array}{r}2 \text { functional } \\
\text { groups }\end{array}$ & $\begin{array}{r}3 \text { functional } \\
\text { groups }\end{array}$ & $\begin{array}{r}>3 \text { functional } \\
\text { groups }\end{array}$ & Non volatile & Semi volatile & Volatile \\
\hline$n$ & 108 & 1179 & 6838 & 107041 & 57772 & 56360 & 1034 \\
\hline MAD JR/MY-SIM & 0.47 & 0.67 & 1.27 & 3.6 & 4.53 & 2.36 & 0.55 \\
\hline MDJR/MY-SIM & 0.12 & -0.26 & -1.14 & -3.59 & -4.53 & -2.31 & 0.12 \\
\hline MADJR/MY-NAN/NAN & 0.44 & 0.84 & 1.31 & 2.23 & 2.49 & 1.95 & 0.58 \\
\hline MDJR/MY-NAN/NAN & -0.33 & -0.7 & -1.23 & -2.2 & -2.36 & -1.91 & -0.43 \\
\hline MAD $_{\text {SIM-NAN/NAN }}$ & 0.48 & 0.59 & 0.57 & 1.52 & 2.17 & 0.73 & 0.61 \\
\hline MDSIM-NAN/NAN & -0.45 & -0.44 & -0.09 & 1.39 & 2.16 & 0.42 & -0.55 \\
\hline
\end{tabular}

number of species in each subset. The number of species increases exponentially with the number of groups as expected from the growth of possible structural isomers (e.g. Aumont et al., 2005; Goldstein and Galbally, 2007; Kroll et al., 2011). The mean difference (MD) and the mean absolute difference (MAD) between the estimated values were calculated for each subset:

$$
\begin{aligned}
& \operatorname{MAD}_{y-x}=\frac{1}{n} \sum_{i}\left|\log _{10} P_{y, i}^{\mathrm{vap}}-\log _{10} P_{x, i}^{\mathrm{vap}}\right| \\
& \mathrm{MD}_{y-x}=\frac{1}{n} \sum_{i}\left(\log _{10} P_{y, i}^{\mathrm{vap}}-\log _{10} P_{x, i}^{\mathrm{vap}}\right)
\end{aligned}
$$

where $n$ is the number of species in the subset and $P_{x, i}^{\text {vap }}$ and $P_{y, i}^{\mathrm{vap}}$ are the vapour pressures estimated for the species $i$ with the $x$ and $y$ SAR, respectively. The MAD and MD values are shown in Table 2 for the various $x-y$ pairs of SAR. The JR/MY method estimates lower $P^{\text {vap }}$ in comparison to NAN/NAN and SIM as already highlighted by previous studies (e.g. Barley and McFiggans, 2010; Compernolle et al., 2010). Discrepancies in the predicted vapour pressures increase with the number of functional groups borne by the species (see Table 2). Agreement is typically within a factor of 3 for mono-functional species and 5 for di-functional species but reaches a factor of 30 (SIM vs. NAN/NAN) to 4000 (JR/MY vs. SIM) for species bearing at least 4 functional groups.

As expected from this result, differences in the predicted values increase as vapour pressure decreases (see Fig. 4). For the subset of volatile species, the estimated $P^{\text {vap }}$ values typically agree within a factor of 4 (see Table 2). For the non-volatile species, the differences in $P^{\text {vap }}$ range from 2 orders of magnitude (SIM vs. NAN/NAN) to almost 5 orders of magnitude (JR/MY vs. SIM). Note however that for atmospheric applications, this strong disagreement should not be a major issue as long as the various methods predict that a given species is non-volatile (i.e. with a vapour pressure below $\left.10^{-13} \mathrm{~atm}\right)$. Models of the formation of SOA are expected to be especially sensitive to the vapour pressure assigned to the semi-volatile subset of species (see Fig. 1) due to representation of the phase partitioning. For this subset of species, the differences in $P^{\text {vap }}$ reach a factor of 5 between the NAN/NAN and SIM estimates, a factor of 90 between the JR/MY and NAN/NAN estimates and a factor of 200 between the SIM and JR/MY estimates (see Table 2). The large discrepancies between estimation methods for these semivolatile species are a likely source of uncertainty when used in modelling studies devoted to SOA formation.

\section{$4 P^{\text {vap }}$ sensitivity of SOA formation}

\subsection{Simulation conditions}

Simulated SOA formation was compared to SOA observations in the Caltech chamber during $\alpha$-pinene oxidation. Three experiments performed under various $\mathrm{NO}_{\mathrm{x}}$ concentrations were selected:

- a "low- $\mathrm{NO}_{\mathrm{x}}$ " experiment, using $\mathrm{H}_{2} \mathrm{O}_{2}$ photolysis to produce $\mathrm{OH}$ radicals.

- an "intermediate- $\mathrm{NO}_{\mathrm{x}}$ " experiment, using $\mathrm{H}_{2} \mathrm{O}_{2}$ photolysis to produce $\mathrm{OH}$ radicals with an initial $\mathrm{NO}_{\mathrm{x}}$ concentration of about $200 \mathrm{ppb}$.

- a "high- $\mathrm{NO}_{\mathrm{x}}$ " experiment, using HONO photolysis to produce $\mathrm{OH}$ radicals with an initial $\mathrm{NO}_{\mathrm{x}}$ concentration of about $1 \mathrm{ppm}$.

Details of these experiments are given by $\mathrm{Ng}$ et al. (2007). Experiments were performed at ambient temperature with low relative humidity $(\sim 5 \%)$ using black light lamps. Inorganic seeds were introduced before the start of each experiment. Initial concentrations of the precursors are given in Table 3. Temperature, relative humidity, $\mathrm{O}_{3}, \mathrm{NO}, \mathrm{NO}_{2}$ 
Table 3. Initial conditions used to simulate $\alpha$-pinene oxidation experiments performed in the Caltech chamber.

\begin{tabular}{|c|c|c|c|}
\hline & Low-NO ${ }_{\mathrm{x}}$ experiment $^{\mathrm{a}}$ & Intermediate- $\mathrm{NO}_{\mathrm{x}}$ experiment ${ }^{\mathrm{b}}$ & High- $\mathrm{NO}_{\mathrm{x}}$ experiment ${ }^{\mathrm{c}}$ \\
\hline \multicolumn{4}{|l|}{ Measured parameters } \\
\hline Temperature & $298 \mathrm{~K}$ & $296 \mathrm{~K}$ & $299 \mathrm{~K}$ \\
\hline Relative humidity & $5.3 \%$ & $6.4 \%$ & $3.3 \%$ \\
\hline$[\alpha \text {-pinene }]_{0}$ & $13.8 \mathrm{ppb}$ & $13.1 \mathrm{ppb}$ & $12.6 \mathrm{ppb}$ \\
\hline$\left[\mathrm{O}_{3}\right]_{0}$ & $4 \mathrm{ppb}$ & & \\
\hline$[\mathrm{NO}]_{0}$ & & $198 \mathrm{ppb}$ & $475 \mathrm{ppb}$ \\
\hline$\left[\mathrm{NO}_{2}\right]_{0}$ & & & $463 \mathrm{ppb}$ \\
\hline \multicolumn{4}{|l|}{ Optimised parameters } \\
\hline$\left[\mathrm{H}_{2} \mathrm{O}_{2}\right]_{0}$ & $4 \mathrm{ppm}$ & $10 \mathrm{ppm}$ & \\
\hline$[\mathrm{HONO}]_{0}$ & & & $400 \mathrm{ppb}$ \\
\hline$\left[\mathrm{NO}_{\mathrm{X}}\right]_{0}$ background & $0.66 \mathrm{ppb}$ & & \\
\hline $\mathrm{NO}_{\mathrm{x}}$ offgassing & $1.5 \mathrm{ppt} \min ^{-1}$ & & \\
\hline OH unknown source & & & $1.8 \times 10^{9}$ molec cm $^{-3} \mathrm{~s}^{-1}$ \\
\hline $\mathrm{J}_{\mathrm{NO} 2}$ & $2.4 \times 10^{-1} \mathrm{~min}^{-1}$ & $2.4 \times 10^{-1} \mathrm{~min}^{-1}$ & $2.4 \times 10^{-1} \mathrm{~min}^{-1}$ \\
\hline $\mathrm{J}_{\mathrm{H} 2 \mathrm{O} 2}$ & $1.7 \times 10^{-4} \min ^{-1}$ & $1.7 \times 10^{-4} \min ^{-1}$ & $1.7 \times 10^{-4} \mathrm{~min}^{-1}$ \\
\hline
\end{tabular}

${ }^{\mathrm{a}}$ experiment $1,{ }^{\mathrm{b}}$ experiment $3,{ }^{\mathrm{c}}$ experiment 4 as described by $\mathrm{Ng}$ et al. (2007).

and SOA concentrations were monitored during each experiment. Experimental aerosols mass given below is wall loss corrected.

Each experiment was simulated with the three distinct chemical schemes generated using either JR/MY, NAN/NAN or SIM to estimate $P^{\text {vap }}$. Some key parameters required to perform the simulation were not measured, e.g. the initial concentrations of $\mathrm{OH}$ precursors, photolysis constants and chamber-specific parameters. These parameters were set to achieve reasonable agreement between the simulated $\mathrm{O}_{3}$, $\mathrm{NO}$, and $\mathrm{NO}_{2}$ concentrations and the observations, especially for the time profile of $\alpha$-pinene removal. The optimised parameters are given in Table 3.

The photolysis frequencies were inferred using the low $\mathrm{NO}_{\mathrm{x}}$ experiment. In this experiment, the initial concentrations are such that the dominant $\mathrm{OH}$ source is the $\mathrm{H}_{2} \mathrm{O}_{2}$ photolysis while the major $\mathrm{OH}$ sink is its reaction with $\mathrm{H}_{2} \mathrm{O}_{2}$. The $\mathrm{OH}$ steady state concentration $\mathrm{C}_{\mathrm{OH}}^{\mathrm{ss}}$ is then given by:

$\mathrm{C}_{\mathrm{OH}}^{\mathrm{ss}} \approx 2 \mathrm{~J}_{\mathrm{H} 2 \mathrm{O} 2} / k$

where $\mathrm{J}_{\mathrm{H} 2 \mathrm{O} 2}$ is the $\mathrm{H}_{2} \mathrm{O}_{2}$ photolysis frequency and $k$ the rate constant for the $\mathrm{H}_{2} \mathrm{O}_{2}+\mathrm{OH}$ reaction. $\mathrm{C}_{\mathrm{OH}}^{\mathrm{ss}}$ can be calculated from the measured $\alpha$-pinene decay, leading to $\mathrm{J}_{\mathrm{H} 2 \mathrm{O} 2}=$ $1.7 \times 10^{-4} \mathrm{~min}^{-1}$ for the conditions of the experiment. All the photolysis rates were then computed using a typical black light spectral distribution weighted to yield this $\mathrm{J}_{\mathrm{H} 2 \mathrm{O} 2}$ value. The obtained $\mathrm{J}_{\mathrm{NO} 2}$ is $0.24 \mathrm{~min}^{-1}$, which is in good agreement with the $0.26 \mathrm{~min}^{-1}$ value measured by $\mathrm{Ng}$ et al. (2007). These computed photolysis frequencies were used for the simulations of the three experiments.
Observed and simulated evolution of gaseous compounds ( $\alpha$-pinene, $\mathrm{O}_{3}, \mathrm{NO}$ and $\mathrm{NO}_{2}$ ) are compared in Fig. S1 (supplementary material). In the low- $\mathrm{NO}_{\mathrm{x}}$ experiment, production of $\mathrm{O}_{3}$ is observed. Although $\mathrm{NO}_{\mathrm{x}}$ levels were under the limit of detection of the instruments, this ozone production gives evidence for the presence of $\mathrm{NO}_{2}$ in the chamber. An initial $\mathrm{NO}_{\mathrm{x}}$ concentration was assumed as well as a source of $\mathrm{NO}_{\mathrm{x}}$ offgassing from the chamber wall (see Table 3). The temporal evolution of $\alpha$-pinene and $\mathrm{O}_{3}$ are well represented by the model (see Fig. S1). The precursor is oxidized in $7 \mathrm{~h}$ and a maximum $\mathrm{O}_{3}$ concentration of about $30 \mathrm{ppb}$ is reached. In this system, $\alpha$-pinene is simulated to be oxidized $\sim 87 \%$ by $\mathrm{OH}$. In the intermediate $\mathrm{NO}_{\mathrm{x}}$ experiment, the decay of $\alpha$-pinene is also well simulated. $\alpha$-pinene is oxidized after half an hour, mainly by reaction with $\mathrm{OH}$ (at $70 \%$ ). The concentration of $\mathrm{O}_{3}$ is well simulated during the first $30 \mathrm{~min}$. but overestimated thereafter. In the high$\mathrm{NO}_{\mathrm{x}}$ experiment, the decay of $\alpha$-pinene is under-predicted, strongly suggesting a missing $\mathrm{OH}$ source (see Fig. S2). Simulations were also performed using the Master Chemical Mechanism (Saunders et al., 2003). Similar results are observed for the evolution of gaseous compounds (see Fig. S2). The disagreement in the simulated $\alpha$-pinene decay seems therefore not specific to GECKO-A. The MCM has been evaluated against several chamber experiments for gas phase chemistry (Pinho et al., 2007) and the similar behaviour of both schemes provides a mutual support for an additional $\mathrm{OH}$ source in the high $\mathrm{NO}_{\mathrm{x}}$ experiment. An "unknown $\mathrm{OH}$ " source of $1.8 \times 10^{9}$ molec $\mathrm{cm}^{-3} \mathrm{~s}^{-1}$ was thus added for the 

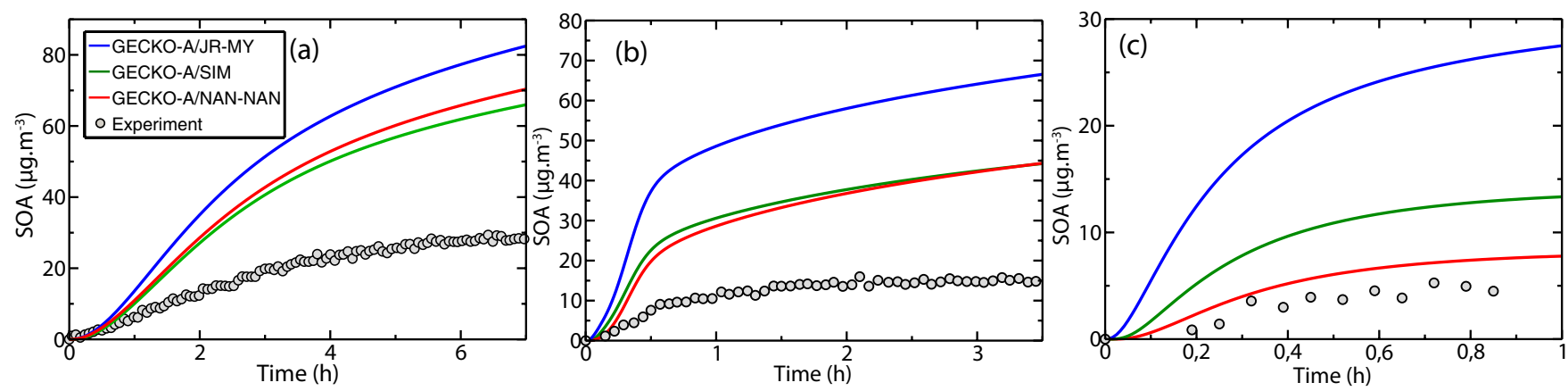

Fig. 5. Time evolution of SOA during $\alpha$-pinene photo oxidation for (a) the low-, (b) intermediate- and (c) high-NO $\mathrm{NO}_{\mathrm{x}}$ experiments. Dots and lines represent, respectively, measurements and values modelled using the various $P^{\mathrm{vap}}$ methods.

simulated $\alpha$-pinene removal to fit the observations, as shown in Fig. S1. The model represents accurately the evolution of $\alpha$-pinene, $\mathrm{NO}$ and $\mathrm{NO}_{2}$ when this "unknown $\mathrm{OH}$ " source is included. In this experiment, the formation of $\mathrm{O}_{3}$ and $\mathrm{NO}_{3}$ are negligible due to the high NO concentration. $\alpha$-pinene is thus oxidized exclusively by $\mathrm{OH}$.

As expected, the gas-phase evolution is essentially independent of the distinct models used to estimate $P^{\text {vap }}$. The discrepancies in the simulated SOA mass with these various models are therefore directly linked to the sensitivity to vapour pressures only.

\subsection{Comparisons of simulated and observed SOA mass}

Observed and simulated SOA mass are compared in Fig. 5. In all experiments, SOA formation is observed as soon as the experiment begins, i.e. when $\alpha$-pinene starts to be oxidized. This behaviour is also simulated by the model. For the low $\mathrm{NO}_{\mathrm{x}}$ experiment, SOA mass is measured to reach a maximum value of $30 \mu \mathrm{g} \mathrm{m}^{-3}$ after $7 \mathrm{~h}$. The SOA mass is well simulated during the first $30 \mathrm{~min}$ followed by an increasing overestimation for the three vapour pressure schemes assessed in this study. At the end of the experiment, SOA mass simulated using JR/MY, NAN/NAN and SIM reaches values of $82 \mu \mathrm{g} \mathrm{m}^{-3}, 70 \mu \mathrm{g} \mathrm{m}^{-3}$ and $66 \mu \mathrm{g} \mathrm{m}^{-3}$, respectively. For this experiment, the simulated SOA mass shows a relatively low sensitivity to $P^{\text {vap }}$ estimation method. In the intermediate- $\mathrm{NO}_{\mathrm{x}}$ experiment, $\mathrm{SOA}$ accumulates during the first $2 \mathrm{~h}$ and reaches a maximum value of about $15 \mu \mathrm{g} \mathrm{m}^{-3}$. The simulated SOA concentrations are overestimated from the beginning of the experiment. At the end of the experiment, the simulated SOA concentrations using JR/MY, NAN/NAN and SIM are $66 \mu \mathrm{g} \mathrm{m}^{-3}, 44 \mu \mathrm{g} \mathrm{m}^{-3}$ and $44 \mu \mathrm{g} \mathrm{m}^{-3}$, respectively. The plateau observed after $2 \mathrm{~h}$ of oxidation in SOA concentration is not captured by the models. The simulated SOA concentrations still show a significant increase after $3 \mathrm{~h}$ of oxidation. In this experiment, the SOA mass simulated with the JR/MY method is overestimated in comparison to the NAN/NAN or SIM method. In the high- $\mathrm{NO}_{\mathrm{x}}$ experiment, observed SOA concentration levels off after $30 \mathrm{~min}$ at $5 \mu \mathrm{g} \mathrm{m}^{-3}$. The simulated mass concentrations are overestimated by the various schemes from the beginning of the experiment. After one hour of oxidation, SOA concentrations reach values of $28 \mu \mathrm{g} \mathrm{m}^{-3}$, $8 \mu \mathrm{g} \mathrm{m}^{-3}$ and $13 \mu \mathrm{g} \mathrm{m}^{-3}$ for the JR/MY, NAN/NAN and SIM schemes, respectively. Simulated SOA concentrations for this $\mathrm{NO}_{\mathrm{x}}$ experiment show the strongest sensitivity to the method used to estimate $P^{\text {vap }}$. The main contributors to the simulated SOA mass have vapour pressure between $10^{-9}$ and $10^{-11} \mathrm{~atm}$ (see Table 4, S1 and S2). As shown in Fig. 1, such species will mostly be found in the aerosol phase $\left(\xi_{i}^{\text {aer }}>0.9\right)$ when the aerosol load exceeds $10 \mu^{-3} \mathrm{~m}^{-3}$ (as in the low- and intermediate- $\mathrm{NO}_{\mathrm{x}}$ experiment). The condensed fraction $\xi_{i}^{\text {aer }}$ shows therefore a low sensitivity to $P^{\text {vap }}$ values and thus $P^{\text {vap }}$ estimates. For conditions where the aerosol concentrations are lower (as in the high- $\mathrm{NO}_{\mathrm{x}}$ experiment), a greater sensitivity of $\xi_{i}^{\text {aer }}$ to $P^{\text {vap }}$ values is observed (see Fig. 5). For the high $\mathrm{NO}_{\mathrm{x}}$ experiment, the major contributors to SOA have $\xi_{i}^{\text {aer }}$ around 0.3 to 0.9 (see Table S2). Note that for atmospheric conditions, sensitivity to vapour pressure is expected to be higher than shown for the smog chambers experiments simulated here due to lower background aerosol concentrations.

Figure 5 shows that while the explicit model captures the qualitative features of SOA formation for these smog chamber experiments, simulated SOA concentrations are systematically overestimated. The model using JR/MY systematically produces the highest SOA yields. This scheme overestimates SOA concentrations by up to a factor of 4 . The model using SIM and NAN/NAN overestimates SOA concentration to a lesser extent, up to a factor of 3 . Based on these 3 experiments, NAN/NAN and SIM methods show the best agreement between observed and simulated SOA. Nevertheless, the simulated SOA concentrations show unexpectedly low sensitivity to the method used to estimate $P^{\text {vap }}$, well below the $P^{\text {vap }}$ variability shown in Sect. 3 for the semi-volatile organic species.

The systematic overestimation of the simulated SOA concentration suggests that processes are either misrepresented 
Table 4. Top 10 species in SOA simulated with SIM in the low $\mathrm{NO}_{\mathrm{x}}$ experiment, with their rank and contribution to the total simulated SOA mass. $\xi_{i}^{\text {aer }}$ is computed at the end of the experiment.

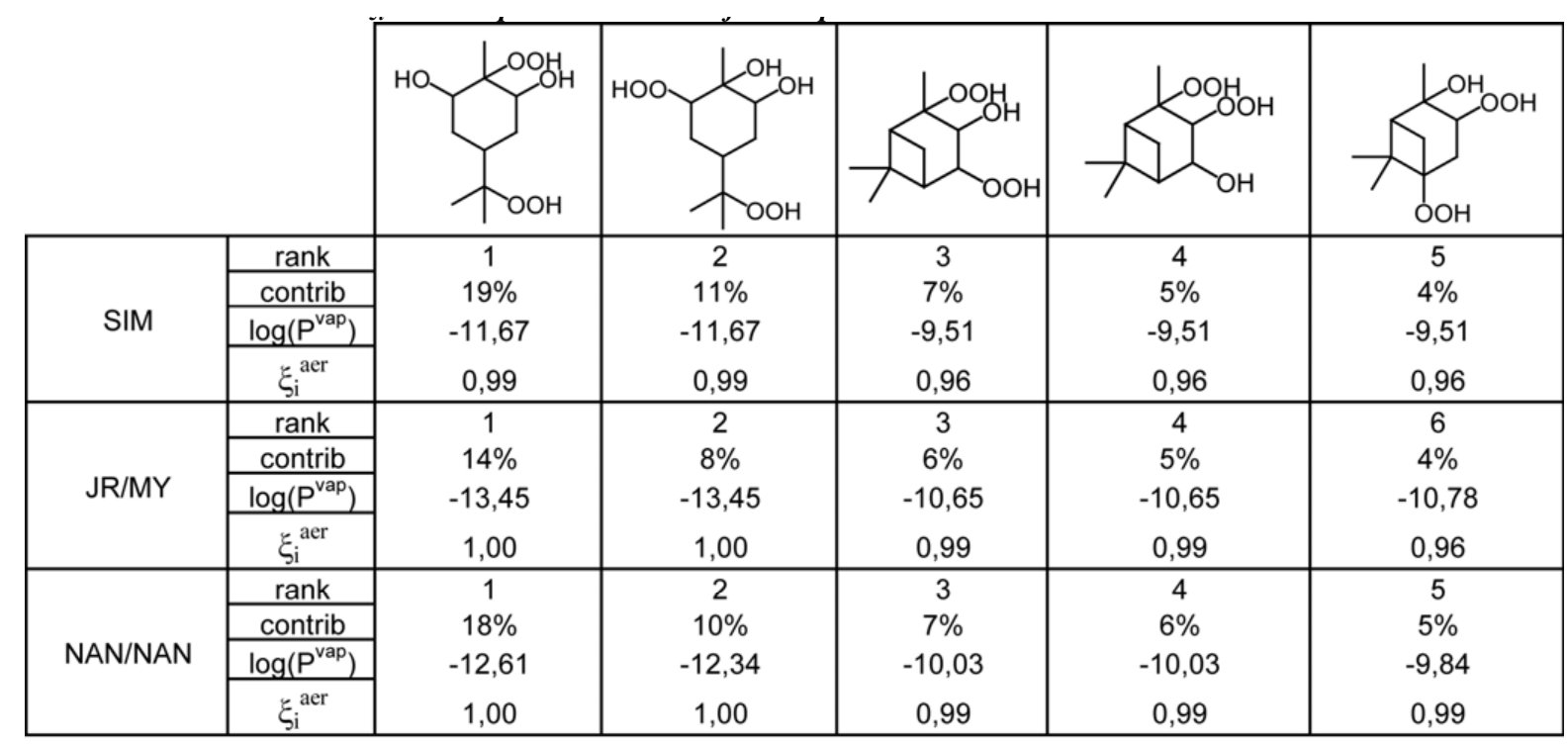

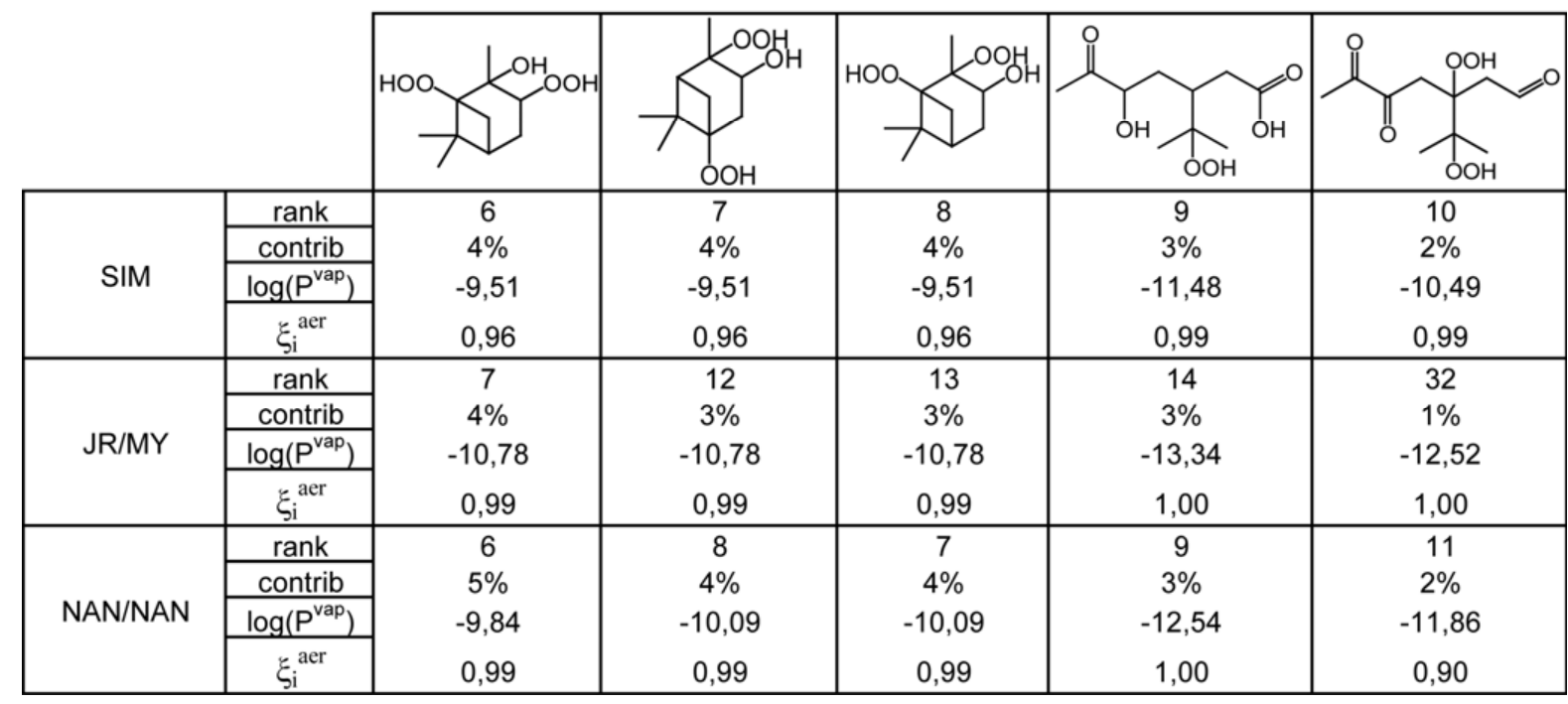

or missing in GECKO-A. One hypothesis could be that the various SAR underestimate $P^{\text {vap }}$ for the semi-volatile species. Such a bias is however difficult to confirm as very few experimental data for the $P^{\text {vap }}$ range of interest are available. We implemented the method combining Nannoolal boiling points with Myrdal and Yalkowsky vapour pressure (hereafter NAN/MY method), known to provide high estimates for $P^{\text {vap }}$ (Barley and McFiggans, 2010). The simulated SOA concentration is given Fig. S5. The results show that the simulated SOA concentration is largely underestimated in the low- and intermediate- $\mathrm{NO}_{\mathrm{x}}$ experiment. In the high- $\mathrm{NO}_{\mathrm{x}}$ experiment, no SOA is simulated using these vapour pressures. These results are consistent with those reported by Compernolle et al. (2010), showing that the use of NAN/MY underpredicted aerosol amounts considerably. These outcomes reinforce the assumption that the systematic overprediction of the simulated SOA concentration might be due to an underprediction of the estimated vapour pressure with 3 methods used in this study. Nevertheless, this hypothesis is not directly sustained by the $\mathrm{O}: \mathrm{C}$ analysis (see Sect. 5.2). Another hypothesis is that the oxidation protocol currently implemented in GECKO-A leads to the formation of secondary compounds for which volatility is too low. In particular, some chemical pathways leading to $\mathrm{C}-\mathrm{C}$ bond breaking could be lacking or misrepresented in the protocol. The simulated major contributor to SOA mass is indeed $\mathrm{C}_{10}$ species (see Sect. 4). Possible oxidation processes occurring in the aerosol phase that lead to the fragmentation of 

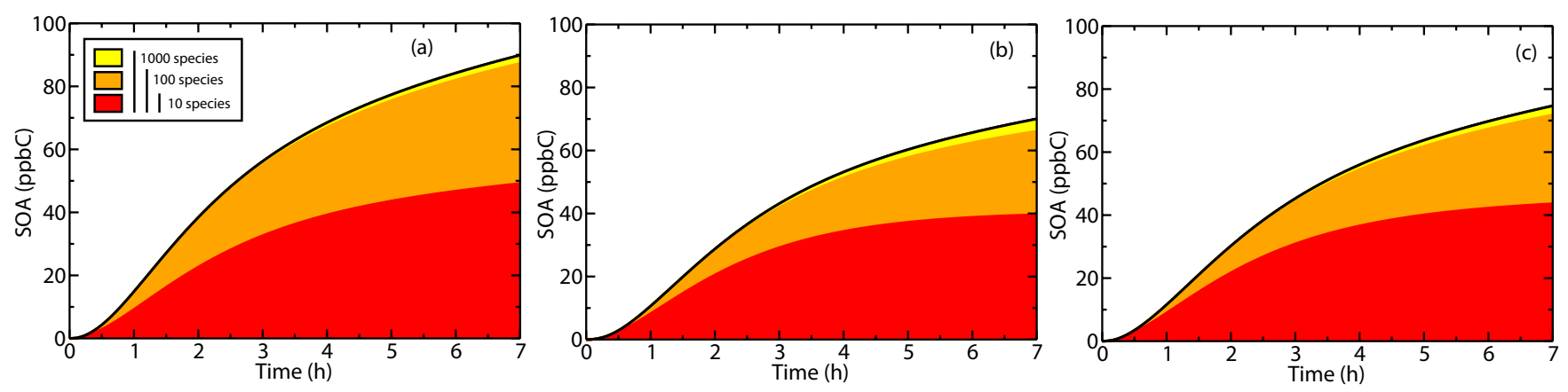

Fig. 6. Contribution of the top 10 (red), top 100 (red + orange) and top 1000 (red + orange + yellow) organic species to the total simulated SOA mass for the low- $\mathrm{NO}_{\mathrm{x}}$ experiment obtained with JR/ MY (a), SIM (b) and NAN/NAN (c).

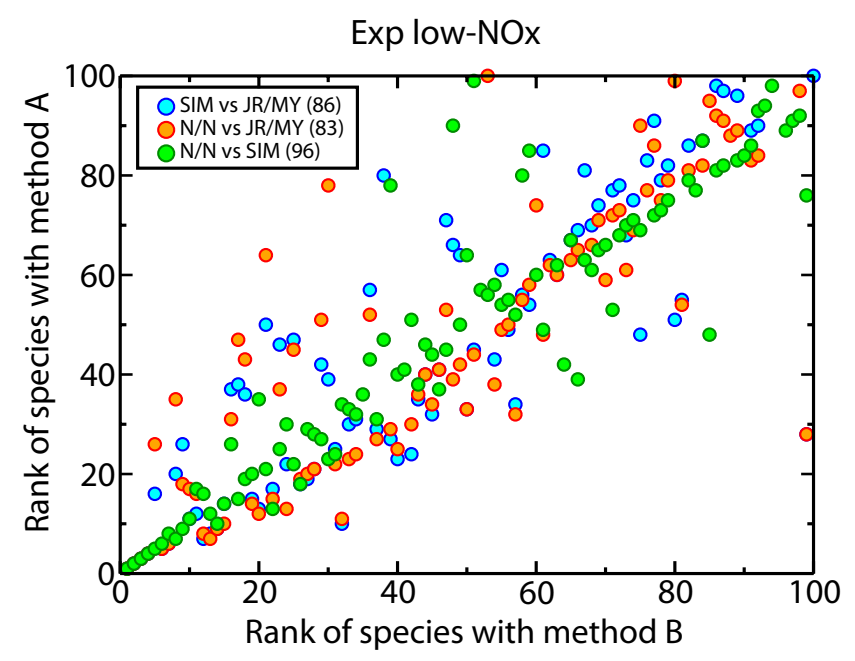

Fig. 7. Comparisons of the ranks of the simulated top 100 organic species between the various methods in the low- $\mathrm{NO}_{\mathrm{x}}$ experiments.

the carbon skeleton, i.e. to volatilization of the aerosol (e.g. Molina et al., 2004; Kroll et al., 2009), are not currently implemented in GECKO-A. A third possibility is that the less volatile species are also removed on the chamber wall (Matsunaga and Ziemann, 2010; Loza et al., 2010). Such uptake of vapours would decrease the gas-phase amount of SOA contributors, therefore lowering the predicted SOA and bringing the model and the observations into closer agreement. In addition, we simulated SOA formation assuming a gas/particle absorptive equilibrium into an ideal liquid phase. Recent studies suggest that the partitioning could occur according to an adsorptive/resublimation process between the gas and an amorphous solid phase (Virtanen et al., 2010; Vaden et al., 2011; Cappa and Wilson, 2011). These new insights could also be a possible explanation for the divergences observed between the experiments and the modelled SOA.

\subsection{Simulated SOA composition}

The simulated SOA composition was investigated at the molecular scale for the three vapour pressure models tested here. Table 4 reports the simulated top 10 species contributing to the total SOA mass with SIM $P^{\text {vap }}$ estimates for the low- $\mathrm{NO}_{\mathrm{x}}$ experiment. Their contribution and ranking simulated with JR/MY and NAN/NAN are also reported. The speciation of these top 10 species as well as their ranking are very similar between SIM, NAN/NAN and JR/MY. The three models predict the same top 4 species. Species are $\mathrm{C}_{10}$ compounds bearing mainly alcohol and hydroperoxide moieties, as expected under low- $\mathrm{NO}_{\mathrm{x}}$ conditions. Figure 6 shows the cumulative contribution of the top 10,100 and 1000 species to the simulated SOA mass for the three models. During the first minutes of oxidation, the top 10 species represent almost the total simulated SOA mass. The complexity of the SOA composition increases as oxidation proceeds, owing to the contribution of the less volatile species produced in the gas-phase from the oxidation of the first-generation species. After $7 \mathrm{~h}$ of oxidation, about 100 species contribute significantly to the SOA mixture. The contribution of the next 1000 species increases slowly but remains low over the timescale of the experiment. Their contribution might, however, be important at longer time scales.

The rankings provided by the three models for the top 100 SOA contributors are compared in Fig. 7. As already shown in Table 4, the leading species are almost the same regardless of the method used to estimate $P^{\text {vap }}$. Among the top 100 species, at least 83 are identical in the simulations using the three $P^{\text {vap }}$ estimation methods. Discrepancies increase for the species of lower ranking. As the contribution of those species to the total SOA mass remain low for the conditions simulated here, this does not significantly influence the simulated SOA concentration.

Similar trends were found for the intermediate- and high$\mathrm{NO}_{\mathrm{x}}$ experiments. Tables S.1 and S.2 in the supplementary material show the simulated top 10 species for these experiments and Fig. S3 gives the cumulative contribution of the top 10, 100 and 1000. As for the low- $\mathrm{NO}_{\mathrm{x}}$ experiment, the 


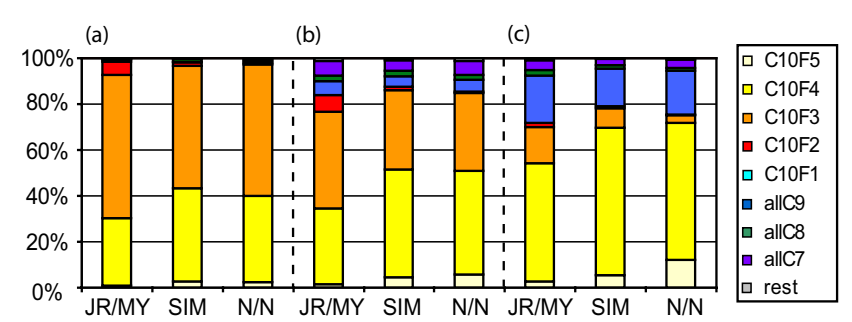

Fig. 8. Simulated distribution of condensed secondary organics as a function of carbon and function at the end of the (a) low-, (b) intermediate- and (c) high- $\mathrm{NO}_{\mathrm{x}}$ experiments. $\mathrm{C} 10 \mathrm{Fi}$ stands for species having 10 carbon atoms and bearing $i$ functional groups. Percentages are computed on a per carbon atom basis.

SOA total mass is only made up of about one hundred species in the high $\mathrm{NO}_{\mathrm{x}}$ experiment and about one thousand species in the intermediate $\mathrm{NO}_{\mathrm{x}}$ experiment among the hundreds of thousands included in the explicit chemical scheme. For the conditions simulated here, SOA speciation therefore appears to be rather insensitive to the $P^{\text {vap }}$ estimation method.

\subsection{Simulated SOA structural properties}

The structural properties of SOA components were investigated for the JR/MY, NAN/NAN and SIM models. Figure 8 shows the simulated distribution of condensed species as a function of the number of carbon atoms and functional groups borne by the molecules. Ratios given in Fig. 8 were computed at the end of the low-, intermediate- and high$\mathrm{NO}_{\mathrm{x}}$ experiments. Condensed organic carbon is dominated by species containing 10 carbon atoms, i.e. of the same size as the precursor, $\alpha$-pinene. In the low- $\mathrm{NO}_{\mathrm{x}}$ experiment, the $\mathrm{C}_{10}$ species bear mainly 3 and 4 functional groups, respectively contributing to $53-62 \%$ and $29-40 \%$ of the condensed organics, depending on the $P^{\text {vap }}$ estimation method. In the high- $\mathrm{NO}_{\mathrm{x}}$ experiment, the $\mathrm{C}_{10}$ species contain mainly 4 functional groups, contributing from 51 to $64 \%$ of the condensed organics according to the method used to estimate $P^{\text {vap. In }}$ all experiments, the JR/MY model calculates lower volatility and therefore promotes the condensation of more volatile species, i.e. species with a shorter carbon skeleton or less functionalised. For example, in the intermediate- $\mathrm{NO}_{\mathrm{x}} \mathrm{ex}-$ periment, di-functionalised $\mathrm{C}_{10}$ species contribute $7 \%$ of the condensed phase with JR/MY, whereas none of these species is a significant SOA contributor in the simulations performed with SIM and NAN/NAN. This is a direct consequence of the lower $P^{\text {vap }}$ estimations provided by JR/MY in comparison to SIM and NAN/NAN (Sect. 3). The NAN/NAN model predicts a larger contribution for low volatility species, i.e. more functionalised species. For example, in the high- $\mathrm{NO}_{\mathrm{x}}$ experiment, $\mathrm{C}_{10}$ species bearing 5 functional groups represent $12 \%$ of SOA mass with NAN/NAN, but only $6 \%$ with SIM and $3 \%$ with JR/MY. This result is a direct consequence of the higher $P^{\text {vap }}$ estimates provided by NAN/NAN in compar-

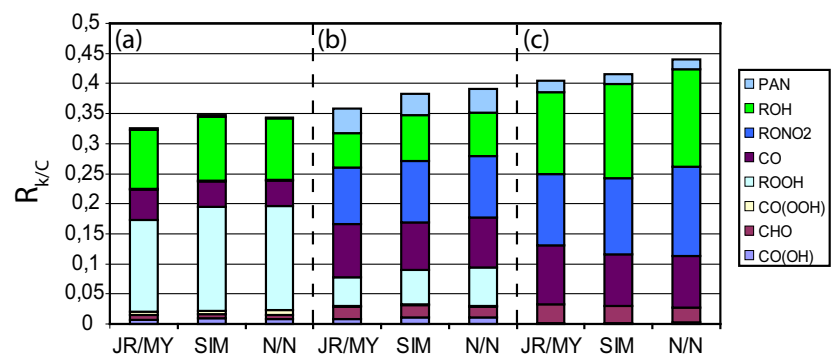

Fig. 9. Simulated distribution of the gaseous and condensed secondary organics as a function of the type of functionality at the end of the (a) low-, (b) intermediate- and (c) high- $\mathrm{NO}_{\mathrm{x}}$ experiments.

ison to SIM and JR/MY. In addition, species partition toward the condensed phase to a lesser extent and will thus undergo further gaseous oxidation, promoting the formation of these highly functionalised species.

The distribution of the different organic moieties in the aerosol phase is shown in Fig. 9 for the three models, at the end of each experiment. Results are expressed as a ratio of organic functional groups per carbon:

$R_{k / C}=\frac{\sum_{i} n_{i}^{k} \times C_{i}}{\sum_{i} n_{i}^{C} \times C_{i}}$

where $C_{i}$ is the concentration of molecule $i$ in the aerosol phase and $n_{i}^{k}$ or $n_{i}^{C}$ are the number of functional groups $k$ and carbon atoms, respectively, in the molecule $i$. The substitution degree of the carbon in the condensed phase, $\sum_{k} R_{k / C}$, ranges between $0.32-0.35,0.36-0.39$, and $0.40-$ 0.44 for the low-, intermediate- and high- $\mathrm{NO}_{\mathrm{x}}$ experiments respectively, depending on the $P^{\text {vap }}$ estimation method. The carbon substitution degree and the O:C and N:C ratios are slightly lower for the MY model, compared to the NAN/NAN and SIM. As discussed above, the JR/MY model leads to the condensation of less oxidized species, which explains the lower substitution degree. In the low- $\mathrm{NO}_{\mathrm{x}}$ experiment, dominant moieties are the hydroperoxide group $\left(\mathrm{R}_{\mathrm{ROOH} / \mathrm{C}}=0.15-0.17\right)$, the alcohol group $\left(\mathrm{R}_{\mathrm{ROH} / \mathrm{C}}=0.10\right)$ and the ketone group $\left(\mathrm{R}_{-} \mathrm{CO}-/ \mathrm{C}=0.04-0.05\right)$. For the high$\mathrm{NO}_{\mathrm{x}}$ experiment, dominant moieties are the aldehyde and ketone groups $\left(\mathrm{R}_{-} \mathrm{CHO} / \mathrm{C}+\mathrm{R}_{-\mathrm{CO}-/ \mathrm{C}}=0.11-0.13\right)$, the alcohol group $\left(\mathrm{R}_{\mathrm{ROH} / \mathrm{C}}=0.14-0.16\right)$ and the nitrate group $\left(\mathrm{R}_{\mathrm{RONO} / \mathrm{C}}=0.12-0.15\right)$. For the conditions simulated here, the JR/MY, NAN/NAN and SIM models provide very similar degrees of substitution of the carbon and functional groups.

\section{Influence of $\mathrm{NO}_{\mathrm{x}}$ levels on gaseous and particulate organic properties}

$\mathrm{NO}_{\mathrm{x}}$ levels govern the distribution of organic species formed during gaseous oxidation, and therefore SOA formation and 

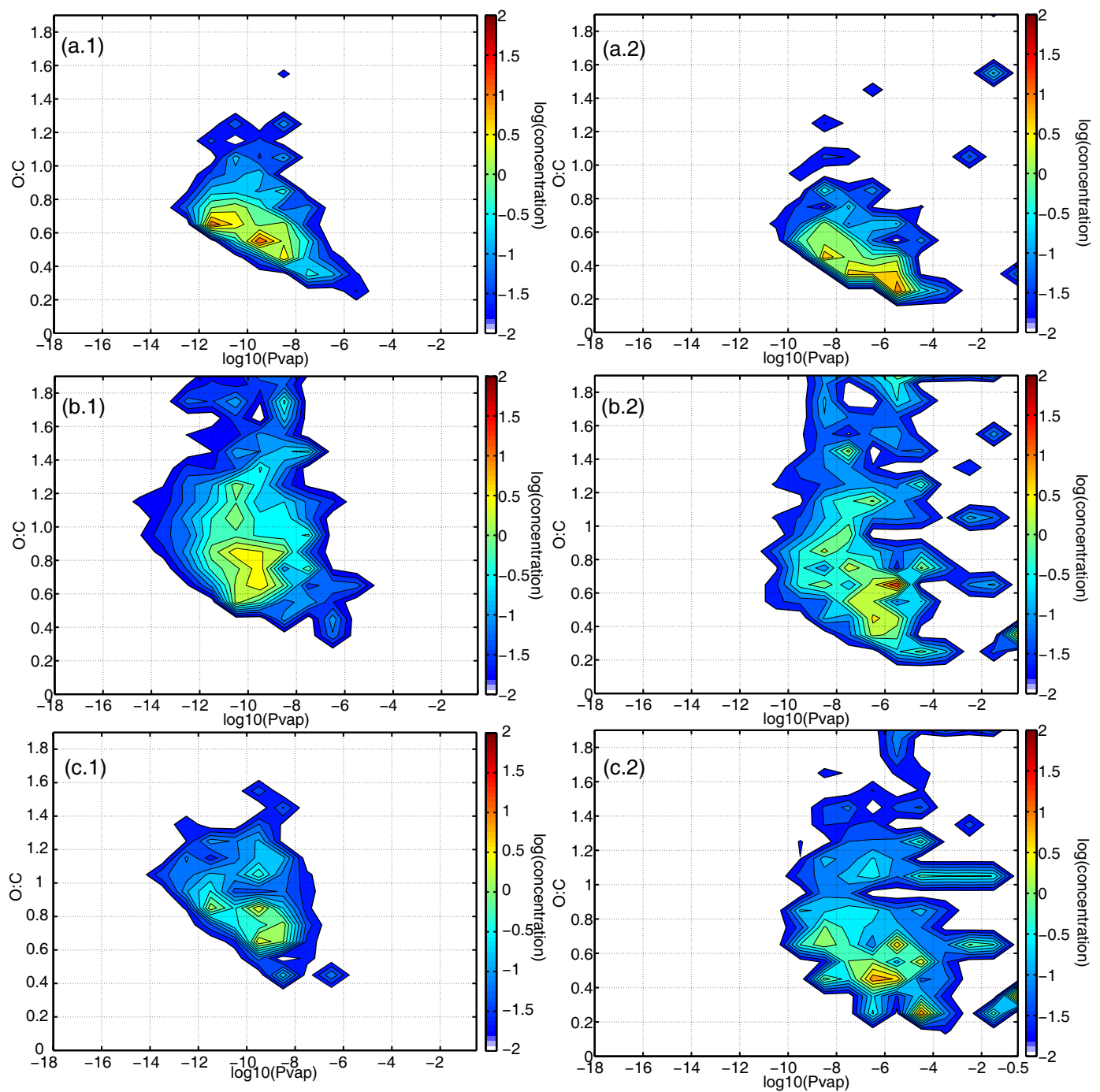

Fig. 10. Simulated distribution of gaseous and condensed secondary organics concentrations in $\mu \mathrm{g} \mathrm{m}{ }^{-3}$ as a function of $P^{\mathrm{vap}}$ (atm) and $\mathrm{O}$ :C ratio at the end of the (a) low, (b) intermediate and (c) high- $\mathrm{NO}_{\mathrm{x}}$ experiments, for the (1) particle, and (2) gas phases.

speciation (Kroll and Seinfeld, 2008). Under low- $\mathrm{NO}_{\mathrm{x}}$ conditions, peroxy radicals $\left(\mathrm{RO}_{2}\right)$ react with $\mathrm{HO}_{2}$ to form hydroperoxides, whereas under high $\mathrm{NO}_{\mathrm{x}}$ conditions, $\mathrm{RO}_{2}$ reacts with NO to form organics nitrates (e.g. Atkinson, 2000), among other products. The presence of hydroperoxides under low $\mathrm{NO}_{\mathrm{x}}$ and nitrates under high $\mathrm{NO}_{\mathrm{x}}$ in gaseous and condensed organic species has been detected experimentally (e.g. Noziere et al., 1999; Reinnig et al., 2009; Rollins et al., 2010) and simulated by models (e.g. Camredon et al., 2007). The dependence of these organic moieties on $\mathrm{NO}_{\mathrm{x}}$ levels is also highlighted in this modelling study (see Fig. 9). Moreover, $\mathrm{NO}_{\mathrm{x}}$ levels influence the number of carbon atoms and functional groups of secondary organics by enhancing the conversion of peroxy radicals into alkoxy radicals (RO). RO undergoes three reaction types (e.g. Atkinson, 2000), which lead either to functionalisation of the carbon skeleton $(\mathrm{H}$ - shift isomerisation or reaction with $\mathrm{O}_{2}$ ) or to its fragmentation (decomposition by $\beta$-scission).

The simulated distributions of O:C ratio in the particle and gas phases can be determined as a function of $P^{\text {vap }}$ to examine the $\mathrm{NO}_{\mathrm{x}}$ influence on the fragmentation and functionalisation processes during oxidation (Jimenez et al., 2009). Results are presented in Fig. 10 for the SIM model at the end of each experiment for the low-, intermediate- and high$\mathrm{NO}_{\mathrm{x}}$ cases. Results obtained with the JR/MY and NAN/NAN models were very similar and are not shown here. In the low$\mathrm{NO}_{\mathrm{x}}$ experiment, SOA exhibit 2 peaks of concentrations (red areas in Fig. 10a.1) at vapour pressure of $10^{-12}$ and $10^{-10}$ atm and at $\mathrm{O}: \mathrm{C}$ ratios of $0.5-0.6$ and $0.6-0.7$, respectively. These areas contain about $50 \%$ of the simulated SOA mass and correspond to the top 10 species presented in Sect. 4 . The major SOA contributors that have similar structures (see 
Table 4) fall into the same area on the plot of O:C ratio vs. $P^{\text {vap }}$. Other SOA contributors account for less than $2 \%$ each to SOA mass (blue to green areas in Fig. 10a.1). The vapour pressures of the species are distributed between $10^{-14}$ to $10^{-5} \mathrm{~atm}$ and the $\mathrm{O}: \mathrm{C}$ ratios range from 0.2 to 1.2 . The shape of the distribution highlights the functionalisation of secondary species (Jimenez et al., 2009), i.e. reducing volatility and increasing oxidation degree of secondary organics. A similar shape is observed in the gas phase. In the presence of $\mathrm{NO}_{\mathrm{x}}$, the organic species distribution shows a different pattern. The gaseous distribution exhibits a wider spread than in low- $\mathrm{NO}_{\mathrm{x}}$ conditions. Secondary organics reach a $\mathrm{O}: \mathrm{C}$ ratios of up to 2 . The shape of the distribution comes from a combination of functionalisation and fragmentation reactions mostly controlled by the reactions of alkoxy radicals. No particle-phase reaction processes are currently implemented in the model. In the last few years, experimental studies have shown the presence of polymerisation reactions in the condensed phase (e.g. Kalberer et al., 2004; Heaton et al., 2007). Accounting for polymerisation reactions would likely produce high molecular mass compounds and shift the distribution toward the lower volatility range.

The aerosol chemical composition was measured using an Aerodyne Quadrupole Aerosol Mass Spectrometer (QAMS) for these experiments (Ng et al., 2007). The O:C ratio has been estimated from the fraction of $m / z 44$ to total signal in the mass spectrum, using the correlation derived by Aiken et al. (2008). The O:C values for these experiments are about $0.3(\mathrm{Ng}$ et al., 2010). The $\mathrm{O}: \mathrm{C}$ ratios simulated with GECKO-A are 0.55 and 0.73 (on average) for the low and high $\mathrm{NO}_{\mathrm{x}}$ experiments, respectively. Theses ratios are twice those estimated from the measured $\mathrm{m} / z 44$ fragment. Recently, high resolution AMS data have become available for $\alpha$-pinene photooxidation experiments performed in the Caltech chamber (Ng et al., 2011; Chhabra et al., 2011). The O:C ratios have been calculated explicitly by elemental analysis. The O:C values are found to be about 0.34 for a low $\mathrm{NO}_{\mathrm{x}}$ experiment and 0.42 and for a high $\mathrm{NO}_{\mathrm{x}}$ experiment, performed under similar conditions. Although these ratios are in better agreement with the values simulated with GECKO-A, the model still overestimates the O:C. This overestimation is consistent with the general overestimation of the SOA yields simulated for these experiments. This supports the hypotheses raised in Sect. 4.2 about the possible processes that may be misrepresented in GECKO-A with the following exception. The likelihood of a $P^{\mathrm{vap}}$ underestimation by the various methods is not directly supported by the $\mathrm{O}: \mathrm{C}$ ratio analysis. Indeed, increasing the vapour pressure decreases the simulated SOA concentration (fewer species condense) but shifts the $\mathrm{O}: \mathrm{C}$ ratio to higher values (species that ultimately condense are more functionalised). For example, the O:C ratio simulated for the low $\mathrm{NO}_{\mathrm{x}}$ experiment using NAN/MY method (see Sect. 4.2) is 0.7. Thus, increasing the vapour pressure would not help to reconcile the differences between simulated and measured O:C values.

\section{Conclusions}

We present detailed simulations of SOA formation from $\alpha$ pinene photooxidation using GECKO-A with three $P^{\text {vap }}$ estimation methods: the Myrdal and Yalkowsky, Nannoolal and SIMPOL methods. Comparisons of JR/MY, NAN/NAN and SIM $P^{\text {vap }}$ estimates for the set of secondary species involved in the $\alpha$-pinene oxidation scheme show large discrepancies. Differences in the predicted $P^{\mathrm{vap}}$ of individual compounds increase with the number of functional groups on the molecule and can reach 5 orders of magnitude for some of the semi-volatile products of $\alpha$-pinene oxidation. These discrepancies between vapour pressure estimation methods are a source of uncertainty in explicit SOA modelling studies.

SOA mass is over-predicted when the model is applied to simulate $\alpha$-pinene photooxidation experiments over a range of $\mathrm{NO}_{\mathrm{x}}$ levels carried out in the Caltech chamber. Observed SOA mass is overestimated by the models, up to a factor of 4 using the JR/MY model and up to a factor of 3 using the SIM and NAN/NAN models. The identity of the main SOA contributors and the mean structural properties (the number of carbon atoms and functional groups borne by the molecules) were investigated for the three models tested here. Despite differences in estimates of $P^{\text {vap }}$ for individual compounds, for the experimental conditions simulated in this study, the speciation does not depend strongly on the $P^{\text {vap }}$ estimation method.

While GECKO-A captures the qualitative features of the $\alpha$-pinene/SOA/ $/ \mathrm{NO}_{\mathrm{x}}$ system, the systematic overestimation of the simulated SOA mass suggests that some processes may be misrepresented or not presently included in GECKOA. These include: (i) underestimation of $P^{\text {vap }}$ for the semivolatile species by the various SAR, (ii) formation of secondary compounds with overly low volatility in the oxidation protocol currently implemented in GECKO-A, (iii) uptake of gaseous semi-volatile organic species on the chamber wall and (iv) the assumption of a gas/particle absorptive equilibrium into an ideal liquid phase instead of a gas/particle adsorptive/resublimation process into an amorphous solid phase. Future sensitivity studies will address these issues.

\section{Supplementary material related to this article is available online at: http://www.atmos-chem-phys.net/11/6895/2011/ acp-11-6895-2011-supplement.pdf.}

Acknowledgements. NCAR is sponsored by the National Science Foundation. JLT was supported and SM was supported in part by a grant from the US Department of Energy, Office of Science, ER, DE-FG02-ER63993.

Edited by: G. McFiggans 


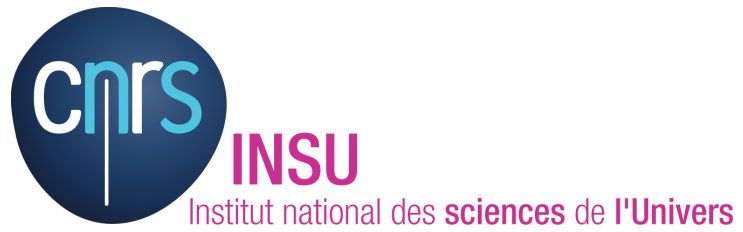

The publication of this article is financed by CNRS-INSU.

\section{References}

Aiken, A. C., DeCarlo, P. F., Kroll, J. H., Worsnop, D. R., Huffman, J. A., Docherty, K. S., Ulbrich, I. M., Mohr, C., Kimmel, J. R., Sueper, D., Sun, Y., Zhang, Q., Trimborn, A., Northway, M., Ziemann, P. J., Canagaratna, M. R., Onasch, T. B., Alfarra, M. R., Prevot, A. S. H., Dommen, J., Duplissy, J., Metzger, A., Baltensperger, U., and Jimenez, J. L.: O/C and OM/OC ratios of primary, secondary, and ambient organic aerosols with high-resolution time-of-flight aerosol mass spectrometry, Environ. Sci. Technol., 42, 4478-4485, 2008.

Atkinson, R.: Atmospheric chemistry of VOCs and NOx, Atmos. Environ., 34, 2063-2101, 2000.

Aumont, B., Szopa, S., and Madronich, S.: Modelling the evolution of organic carbon during its gas-phase tropospheric oxidation: development of an explicit model based on a self generating approach, Atmos. Chem. Phys., 5, 2497-2517, doi:10.5194/acp-52497-2005, 2005.

Barley, M. H. and McFiggans, G.: The critical assessment of vapour pressure estimation methods for use in modelling the formation of atmospheric organic aerosol, Atmos. Chem. Phys., 10, 749767, doi:10.5194/acp-10-749-2010, 2010.

Booth, A. M., Barley, M. H., Topping, D. O., McFiggans, G., Garforth, A., and Percival, C. J.: Solid state and sub-cooled liquid vapour pressures of substituted dicarboxylic acids using Knudsen Effusion Mass Spectrometry (KEMS) and Differential Scanning Calorimetry, Atmos. Chem. Phys., 10, 4879-4892, doi:10.5194/acp-10-4879-2010, 2010

Booth, A. M., Montague, W. J., Barley, M. H., Topping, D. O., McFiggans, G., Garforth, A., and Percival, C. J.: Solid state and subcooled liquid vapour pressures of cyclic aliphatic dicarboxylic acids, Atmos. Chem. Phys., 11, 655-665, doi:10.5194/acp-11655-2011, 2011.

Camredon, M. and Aumont, B.: Assessment of vapor pressure estimation methods for secondary organic aerosol modeling, Atmos. Environ., 40, 2105-2116, doi:10.1016/j.atmosenv.2005.11.051, 2006.

Camredon, M., Aumont, B., Lee-Taylor, J., and Madronich, S.: The SOA/VOC/NO $\mathrm{N}_{\mathrm{x}}$ system: an explicit model of secondary organic aerosol formation, Atmos. Chem. Phys., 7, 5599-5610, doi:10.5194/acp-7-5599-2007, 2007.

Camredon, M., Hamilton, J. F., Alam, M. S., Wyche, K. P., Carr, T., White, I. R., Monks, P. S., Rickard, A. R., and Bloss, W. J.: Distribution of gaseous and particulate organic composition during dark ?-pinene ozonolysis, Atmos. Chem. Phys., 10, $2893-$ 2917, doi:10.5194/acp-10-2893-2010, 2010.

Capouet, M. and Müller, J.-F.: A group contribution method for estimating the vapour pressures of $\alpha$-pinene oxidation products, Atmos. Chem. Phys., 6, 1455-1467, doi:10.5194/acp-6-14552006, 2006.
Capouet, M., Muller, J. F., Ceulemans, K., Compernolle, S., Vereecken, L., and Peeters, J.: Modeling aerosol formation in alpha-pinene photo-oxidation experiments, J. Geophys. Res.Atmos., 113(22), D02308 doi:10.1029/2007jd008995, 2008.

Cappa, C. D. and Wilson, K. R.: Evolution of organic aerosol mass spectra upon heating: implications for OA phase and partitioning behavior, Atmos. Chem. Phys., 11, 1895-1911, doi:10.5194/acp11-1895-2011, 2011.

Chhabra, P. S., Ng, N. L., Canagaratna, M. R., Corrigan, A. L., Russell, L. M., Worsnop, D. R., Flagan, R. C., and Seinfeld, J. H.: Elemental composition and oxidation of chamber organic aerosol, Atmos. Chem. Phys. Discuss., 11, 10305-10342, doi:10.5194/acpd-11-10305-2011, 2011.

Clegg, S. L., Kleeman, M. J., Griffin, R. J., and Seinfeld, J. H.: Effects of uncertainties in the thermodynamic properties of aerosol components in an air quality model - Part 2: Predictions of the vapour pressures of organic compounds, Atmos. Chem. Phys., 8, 1087-1103, doi:10.5194/acp-8-1087-2008, 2008.

Compernolle, S., Ceulemans, K., and Müller, J.-F.: Technical Note: Vapor pressure estimation methods applied to secondary organic aerosol constituents from $\alpha$-pinene oxidation: an intercomparison study, Atmos. Chem. Phys., 10, 6271-6282, doi:10.5194/acp-10-6271-2010, 2010.

Donahue, N. M., Robinson, A. L., and Pandis, S. N.: Atmospheric organic particulate matter: From smoke to secondary organic aerosol, Atmos. Environ., 43, 94-106, doi:10.1016/j.atmosenv.2008.09.055, 2009.

Fuzzi, S., Andreae, M. O., Huebert, B. J., Kulmala, M., Bond, T. C., Boy, M., Doherty, S. J., Guenther, A., Kanakidou, M., Kawamura, K., Kerminen, V.-M., Lohmann, U., Russell, L. M., and Pöschl, U.: Critical assessment of the current state of scientific knowledge, terminology, and research needs concerning the role of organic aerosols in the atmosphere, climate, and global change, Atmos. Chem. Phys., 6, 2017-2038, doi:10.5194/acp-62017-2006, 2006.

Goldstein, A. H. and Galbally, I. E.: Known and unexplored organic constituents in the earth's atmosphere, Environ. Sci. Technol., 41, 1514-1521, 2007.

Hallquist, M., Wenger, J. C., Baltensperger, U., Rudich, Y., Simpson, D., Claeys, M., Dommen, J., Donahue, N. M., George, C., Goldstein, A. H., Hamilton, J. F., Herrmann, H., Hoffmann, T., Iinuma, Y., Jang, M., Jenkin, M. E., Jimenez, J. L., Kiendler-Scharr, A., Maenhaut, W., McFiggans, G., Mentel, Th. F., Monod, A., Prévôt, A. S. H., Seinfeld, J. H., Surratt, J. D., Szmigielski, R., and Wildt, J.: The formation, properties and impact of secondary organic aerosol: current and emerging issues, Atmos. Chem. Phys., 9, 5155-5236, doi:10.5194/acp-95155-2009, 2009.

Heaton, K. J., Dreyfus, M. A., Wang, S., and Johnston, M. V.: Oligomers in the early stage of biogenic secondary organic aerosol formation and growth, Environ. Sci. Technol., 41, 6129_ 6136, doi:10.1021/es070314n, 2007.

Jimenez, J. L., Canagaratna, M. R., Donahue, N. M., Prevot, A. S. H., Zhang, Q., Kroll, J. H., DeCarlo, P. F., Allan, J. D., Coe, H., Ng, N. L., Aiken, A. C., Docherty, K. S., Ulbrich, I. M., Grieshop, A. P., Robinson, A. L., Duplissy, J., Smith, J. D., Wilson, K. R., Lanz, V. A., Hueglin, C., Sun, Y. L., Tian, J., Laaksonen, A., Raatikainen, T., Rautiainen, J., Vaattovaara, P., Ehn, M., Kulmala, M., Tomlinson, J. M., Collins, D. R., Cubison, M. 
J., Dunlea, E. J., Huffman, J. A., Onasch, T. B., Alfarra, M. R., Williams, P. I., Bower, K., Kondo, Y., Schneider, J., Drewnick, F., Borrmann, S., Weimer, S., Demerjian, K., Salcedo, D., Cottrell, L., Griffin, R., Takami, A., Miyoshi, T., Hatakeyama, S., Shimono, A., Sun, J. Y., Zhang, Y. M., Dzepina, K., Kimmel, J. R., Sueper, D., Jayne, J. T., Herndon, S. C., Trimborn, A. M., Williams, L. R., Wood, E. C., Middlebrook, A. M., Kolb, C. E., Baltensperger, U., and Worsnop, D. R.: Evolution of Organic Aerosols in the Atmosphere, Science, 326, 1525-1529, doi:10.1126/science.1180353, 2009.

Joback, K. G. and Reid, R. C.: Estimation of Pure-Component Properties from Group-Contributions, Chem. Eng. Commun., 57, 233-243, 1987.

Kalberer, M., Paulsen, D., Sax, M., Steinbacher, M., Dommen, J., Prevot, A. S. H., Fisseha, R., Weingartner, E., Frankevich, V., Zenobi, R., and Baltensperger, U.: Identification of polymers as major components of atmospheric organic aerosols, Science, 303, 1659-1662, 2004.

Kroll, J. H. and Seinfeld, J. H.: Chemistry of secondary organic aerosol: Formation and evolution of low-volatility organics in the atmosphere, Atmos. Environ., 42, 3593-3624, doi:10.1016/j.atmosenv.2008.01.003, 2008.

Kroll, J. H., Smith, J. D., Che, D. L., Kessler, S. H., Worsnop, D. R., and Wilson, K. R.: Measurement of fragmentation and functionalization pathways in the heterogeneous oxidation of oxidized organic aerosol, Phys. Chem. Chem. Phys., 11, 8005-8014, doi:10.1039/b905289e, 2009.

Kroll, J. H., Donahue, N., Jimenez, J. L., Kessler, S. H., Canagaratna, M. R., Wilson, E. R., Altieri, K. E., R., M. L., Wozniak, A. S., Bluhm, H., Mysak, E. R., Smith, J. D., Kolb, C. E., and Worsnop, D. R.: Carbon oxidation state as a metric for describing the chemistry of atmospheric organic aerosol, Nature Chemistry, 3, 133-139, 2011.

Loza, C. L., Chan, A. W. H., Galloway, M. M., Keutsch, F. N., Flagan, R. C., and Seinfeld, J. H.: Characterization of Vapor Wall Loss in Laboratory Chambers, Environ. Sci. Technol., 44, 50745078, doi:10.1021/es100727v, 2010.

Matsunaga, A. and Ziemann, P.: Gas-wall partitioning of organic compounds in a teflon film chamber and potential effects on reaction product and aerosol yield measurements, Aerosol Sci. Technol., 44, 881-892, 2010.

Molina, M. J., Ivanov, A. V., Trakhtenberg, S., and Molina, L. T.: Atmospheric evolution of organic aerosol, Geophys. Res. Lett., 31(5), L22104 doi:10.1029/2004g1020910, 2004.

Moller, B., Rarey, J., and Ramjugernath, D.: Estimation of the vapour pressure of non-electrolyte organic compounds via group contributions and group interactions, J. Mol. Liq., 143, 52-63, doi:10.1016/j.molliq.2008.04.020, 2008.

Myrdal, P. B. and Yalkowsky, S. H.: Estimating pure component vapor pressures of complex organic molecules, Ind. Eng. Chem. Res., 36, 2494-2499, 1997.

Nannoolal, Y., Rarey, J., Ramjugernath, D., and Cordes, W.: Estimation of pure component properties: Part 1. Estimation of the normal boiling point of non-electrolyte organic compounds via group contributions and group interactions, Fluid Phase Equilibria, 226, 45-63, 2004.

Nannoolal, Y., Rarey, J., and Ramjugernath, D.: Estimation of pure component properties: Part 3. Estimation of the vapor pressure of non-electrolyte organic compounds via group contributions and group interactions, Fluid Phase Equilibria, 269, 117-133, 2008.

Ng, N. L., Chhabra, P. S., Chan, A. W. H., Surratt, J. D., Kroll, J. H., Kwan, A. J., McCabe, D. C., Wennberg, P. O., Sorooshian, A., Murphy, S. M., Dalleska, N. F., Flagan, R. C., and Seinfeld, J. H.: Effect of $\mathrm{NO}_{\mathrm{x}}$ level on secondary organic aerosol (SOA) formation from the photooxidation of terpenes, Atmos. Chem. Phys., 7, 5159-5174, doi:10.5194/acp-7-5159-2007, 2007.

Ng, N. L., Canagaratna, M. R., Zhang, Q., Jimenez, J. L., Tian, J., Ulbrich, I. M., Kroll, J. H., Docherty, K. S., Chhabra, P. S., Bahreini, R., Murphy, S. M., Seinfeld, J. H., Hildebrandt, L., Donahue, N. M., DeCarlo, P. F., Lanz, V. A., Prévôt, A. S. H., Dinar, E., Rudich, Y., and Worsnop, D. R.: Organic aerosol components observed in Northern Hemispheric datasets from Aerosol Mass Spectrometry, Atmos. Chem. Phys., 10, 46254641, doi:10.5194/acp-10-4625-2010, 2010.

Ng, N. L., Canagaratna, M. R., Jimenez, J. L., Chhabra, P. S., Seinfeld, J. H., and Worsnop, D. R.: Changes in organic aerosol composition with aging inferred from aerosol mass spectra, Atmos. Chem. Phys., 11, 6465-6474, doi:10.5194/acp-11-64652011, 2011.

Noziere, B., Barnes, I., and Becker, K. H.: Product study and mechanisms of the reactions of alpha-pinene and of pinonaldehyde with OH radicals, J. Geophys. Res.-Atmos., 104, 23645-23656, 1999.

Pankow, J. F.: An Absorption-Model of the Gas Aerosol Partitioning Involved in the Formation of Secondary Organic Aerosol, Atmos. Environ., 28, 189-193, 1994.

Pankow, J. F. and Asher, W. E.: SIMPOL.1: a simple group contribution method for predicting vapor pressures and enthalpies of vaporization of multifunctional organic compounds, Atmos. Chem. Phys., 8, 2773-2796, doi:10.5194/acp-8-27732008, 2008.

Peeters, J., Vereecken, L., and Fantechi, G.: The detailed mechanism of the $\mathrm{OH}$-initiated atmospheric oxidation of alpha-pinene: a theoretical study, Phys. Chem. Chem. Phys., 3, 5489-5504, 2001.

Pinho, P. G., Pio, C. A., Carter, W. P. L., and Jenkin, M. E.: Evaluation of alpha- and beta-pinene degradation in the detailed tropospheric chemistry mechanism, MCM v3.1, using environmental chamber data, J. Atmos. Chem., 57, 171-202, doi:10.1007/s10874-007-9071-0, 2007.

Reinnig, M. C., Warnke, J., and Hoffmann, T.: Identification of organic hydroperoxides and hydroperoxy acids in secondary organic aerosol formed during the ozonolysis of different monoterpenes and sesquiterpenes by on-line analysis using atmospheric pressure chemical ionization ion trap mass spectrometry, Rapid Commun. Mass Spectrom., 23, 1735-1741, doi:10.1002/rcm.4065, 2009.

Rollins, A. W., Smith, J. D., Wilson, K. R., and Cohen, R. C.: Real Time In Situ Detection of Organic Nitrates in Atmospheric Aerosols, Environ. Sci. Technol., 44, 5540-5545, doi:10.1021/es100926x, 2010.

Saunders, S. M., Jenkin, M. E., Derwent, R. G., and Pilling, M. J.: Protocol for the development of the Master Chemical Mechanism, MCM v3 (Part A): tropospheric degradation of nonaromatic volatile organic compounds, Atmos. Chem. Phys., 3, 161-180, doi:10.5194/acp-3-161-2003, 2003.

Vaden, T. D., Imre, D., Beranek, J., Shrivastava, M., and Zelenyuk, A.: Evaporation kinetics and phase of laboratory and ambient 
secondary organic aerosol, Proc. Natl. Acad. Sci. USA, 108, 2190-2195, doi:10.1073/pnas.1013391108, 2011.

Verwer, J. G. and Vanloon, M.: An Evaluation of Explicit PseudoSteady-State Approximation Schemes for Stiff Ode Systems from Chemical-Kinetics, J. Comput. Phys., 113, 347-352, 1994.

Verwer, J. G., Blom, J. G., VanLoon, M., and Spee, E. J.: A comparison of stiff ODE solvers for atmospheric chemistry problems, Atmos. Environ., 30, 49-58, 1996.
Virtanen, A., Joutsensaari, J., Koop, T., Kannosto, J., Yli-Pirila, P., Leskinen, J., Makela, J. M., Holopainen, J. K., Poschl, U., Kulmala, M., Worsnop, D. R., and Laaksonen, A.: An amorphous solid state of biogenic secondary organic aerosol particles, Nature, 467, 824-827, 10.1038/nature09455, 2010.

Xia, A. G., Michelangeli, D. V., and Makar, P. A.: Box model studies of the secondary organic aerosol formation under different HC/NOx conditions using the subset of the Master Chemical Mechanism for alpha-pinene oxidation, J. Geophys. Res., 113, D10301, doi:10.1029/2007JD008726, 2008. 